\title{
Periodic Unsteady Flow Aerodynamics and Heat Transfer: Studies on a Curved Surface, Combined Part I and II
}

\author{
M.T. SCHOBEIRI*, L. WRIGHT and P. CHAKKA \\ Turbomachinery Performance Laboratory, Texas A\&M University, College Station, TX 77843-3123, USA
}

(Received 4 September 1998)

\begin{abstract}
Aerodynamic and heat transfer investigations were done on a constant curvature curved plate in a subsonic wind tunnel facility for various wake passing frequencies and zero pressure gradient conditions. Steady and unsteady boundary layer transition measurements were taken on the concave surface of the curved plate at different wake passing frequencies where a rotating squirrel-cage generated the unsteady wake flow. The data were analyzed using timeaveraged and ensemble-averaged techniques to provide insight into the growth of the boundary layer and transition. Ensemble-averaged turbulence intensity contours in the temporal spatial domain showed that transition was induced for increasing wake passing frequency and structure. The local heat transfer coefficient distribution for the concave and convex surface was determined at those wake passing frequencies using a liquid crystal heat transfer measurement technique. Detailed aerodynamic and heat transfer investigations showed that higher wake passing frequency caused transition to occur earlier on the concave surface. Local Stanton numbers were also calculated on the concave surface and compared with Stanton numbers predicted using a differential boundary layer and heat transfer calculation method. On the convex side, no effect of wake passing frequency on heat transfer was observed due to a separation bubble that induced transition.
\end{abstract}

Keywords: Unsteady aerodynamics, Heat transfer, Curved surface

\section{INTRODUCTION}

The flow within a gas turbine component is characterized as periodic unsteady wake flow due to the interaction between the rotor and stator. The unsteady wakes result from a velocity defect occurring at the trailing edge of each turbine blade, pass through the blade rows, and alter the natural boundary layer development, the boundary layer transition region, the efficiency of the blade rows, and the heat transfer characteristics of each cascade. From a thermal design stand point, knowledge of the state of the boundary layer is crucial in designing cooling schemes that effectively

*Corresponding author. Tel.: 409 845-0819. Fax: 409 845-3081. E-mail: tshobeiri@mengr.tamu.edu. 
counteract the development of excessive temperature distributions. These schemes allow turbines to operate reliably at higher temperatures and result in increased thermal efficiency and higher specific mechanical energy. Successful prediction of the boundary layer transition allows designers to find the turbine stage efficiency and heat transfer characteristics. However, due to a lack of understanding of the interaction of the unsteady wakes, boundary layer transition has not been predicted reliably. This investigation focuses on the effect that periodic unsteady wakes have upon boundary layer transition and the convective heat transfer characteristics of a curved plate, which simulates the pressure surface of a turbine blade. The results will be used to assess and evaluate the validity of unsteady boundary layer transition models.

Many studies have been done on the effect of periodic unsteady wakes on boundary layer transition. Speidel (1957) was one researcher to investigate unsteady flow. He found that the wakes produced by oscillating cylinders affect the boundary layer of a downstream airfoil and increase its profile loss. Pfeil et al. performed the first significant unsteady periodic research (1983). They used a rotating squirrel-cage to produce periodic wakes on a flat plate, and found that the wake flow induced transition earlier than steady flow and that the end of forced transition did not depend on the end of natural transition. The result was a wakeinduced transition model now generally accepted as correct.

Hodson (1984) and Addison and Hodson (1990a,b) studied the wake effect in a single stage turbine. LaGraff et al. (1989), Ashworth et al. (1989), Liu and Rodi (1992), and Schobeiri et al. (1995b) studied the wake effect in a linear turbine cascade facility. Boundary layer transition models for wake-induced transition have been developed by Walker (1974), Doorly (1988), Sharma et al. (1988), Addison and Hodson (1990a,b), and Mayle and Dullenkopf $(1989,1991)$. However, none are applicable to an unsteady flow situation. Gaugler (1985) and Schobeiri et al. (1991) proved that existing correlations for external aerodynamic applications cannot correctly predict the unsteady transition behavior of gas turbine blades. Thus, more research is needed to correct this situation.

Schobeiri and Pardivala (1992), Schobeiri and Radke (1994), and Schobeiri et al. (1995a,b) performed systematic experimental investigations on the effect of periodic unsteady flow on a concave surface. Schobeiri and Radke observed that the wake flow affects the boundary layer transition leading to the formation of a primary boundary layer that possesses a quasi-steady characteristic and a periodic unsteady, secondary boundary layer resulting from the interaction of the wake strips and the surface of the curved plate. The secondary boundary layer was found to undergo a periodic transition process and convect toward the primary boundary layer leaving becalmed quasi-laminar regions. It was also found that a favorable pressure gradient retards transition. Schobeiri et al. (1995a) continued this work and studied the effect of wake passing frequency on boundary layer transition on a curved plate with zero longitudinal pressure gradient. Besides the aforementioned results, it was found that an increase in wake passing frequency results in a shift of the transition region toward the leading edge due to increased turbulence activities.

Dunn (1986), Dring et al. (1986), Wittig et al. (1988), Dullenkopf et al. (1991), Liu and Rodi (1992), and Han et al. (1993) studied the effect that periodic unsteady wakes have upon heat transfer. Liu and Rodi used a rotating squirrel-cage-type wake generator, while Wittig et al., Dullenkopf et al., and Han et al. used a spoked wheel-type wake generator. Dunn (1986) and Doorly et al. (1985) determined the heat transfer coefficient by using quick response sensors to detect the real time variation on the blade surface heat transfer induced by unsteady wakes. However, Liu and Rodi, Wittig et al. and Dullenkopf et al. used thermocouples to measure the time-averaged heat transfer coefficient. The investigations have shown that periodic unsteady wakes increase the mean heat transfer. Dullenkopf $e t$ al. and Han et al. found that higher wake passing frequency significantly enhances the heat transfer on both the suction and pressure 
surface of a turbine blade due to increased background turbulence. They also found that the suction surface has a higher average heat transfer coefficient than the pressure surface.

The present investigation includes aerodynamic and heat transfer experiments detailed in the following sections. Systematic unsteady boundary layer experiments on the concave surface give a clear picture of the unsteady wake flow and its impact on boundary layer transition. Likewise, detailed liquid crystal measurements on the concave and convex surfaces determine the heat transfer behavior of both surfaces under steady and unsteady flow conditions. A detailed analysis of the influence of unsteady wakes on aerodynamics is performed, followed by an analysis of unsteady wakes on heat transfer. Finally, the paper concludes with a comparison between the experimental results and theory.

\section{SIMULATION OF UNSTEADY MULTISTAGE TURBINE FLOW ENVIRONMENT}

Figure 1 shows a schematic picture of the wake flow within a multistage turbine in an absolute and relative frame of reference. The structure of the unsteady turbulent flow changes as it passes successively through the stator and rotor rows. Leaving the first stator blade row, the wake flow generated at the stator exit impinges on the second blade row (rotor) with a spatial frequency that corresponds to the spacing of the preceding stator blades. Due to the frame of reference change, the second cascade is exposed to a periodic unsteady turbulent flow that affects the boundary layer flow pattern, velocity, turbulence, normal and shear stress, and thus the loss distribution. The third row (second stator) is subjected to two sets of unsteady wakes that originate from the first two rows. These sets of wakes impinge on the third row and convect with different velocities, phase displacements, and turbulence structures. The mutual interaction, dissipation, and mixing of the involved individual wakes

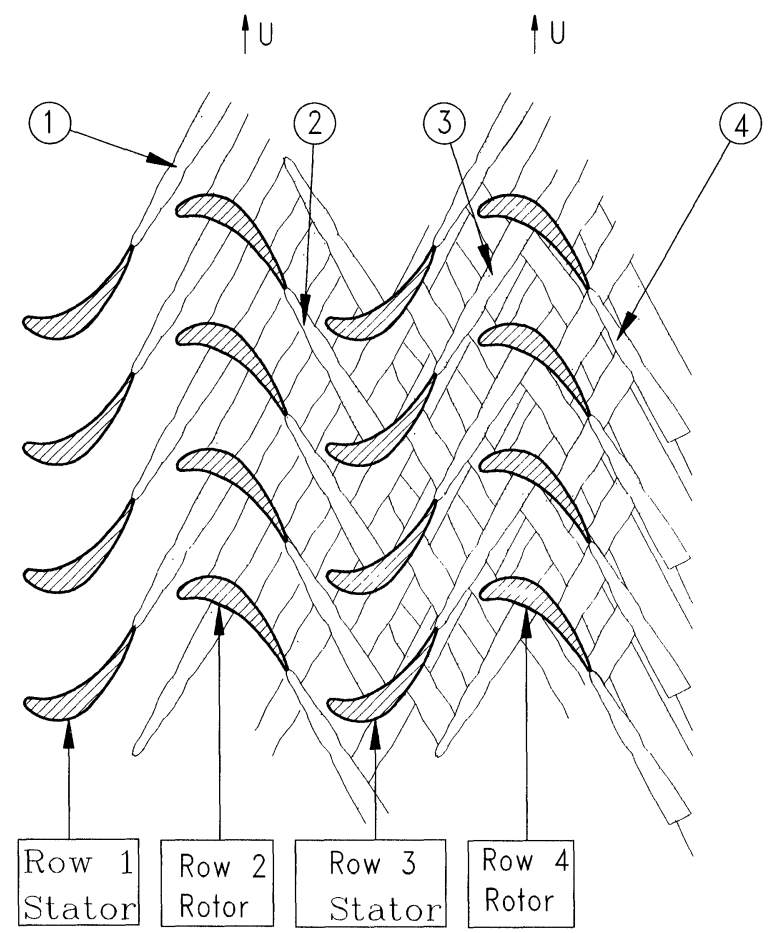

FIGURE 1 Stator-rotor wake interaction in a multistage environment, 1. Absolute wake from row 1 (stator), 2. relative wake from row 2 (rotor), 3. absolute wake from row 1 (stator), 4. relative wake from row 2 (rotor).

already affect the latter. At the exit of the third row, because of intensive interaction and mixing, the deterministic character of the periodic unsteady flow is, to some extent, degenerated into a highly stochastic one. From this point on, the downstream rows are subjected to a highly turbulent flow, with an intensity distribution far above the inlet one. This complex flow picture suggests that boundary layer transition along the blade of each row within a multistage arrangement is subjected to distinctively different unsteady flow structures.

\section{EXPERIMENTAL RESEARCH}

The objective of this investigation is to get essential experimental data to assess and validate unsteady boundary layer transition models. Boundary layer data are collected via a hot-wire anemometry 
system. A state of the art liquid crystal measurement technique was used to obtain the heat transfer distribution on the plate. The boundary layer measurements are done on the concave surface of a curved plate in the presence of wakes generated by a wake generator (Fig. 2). Changing the number of rods varies the wake spacing, which results in a change in frequency of the impinging wakes and freestream turbulence. This method simulates the previously described multistage turbine flow environment. Heat transfer measurements are done on the concave and convex surfaces of a curved heat transfer plate to find the time-averaged heat transfer coefficient distribution for each surface.

The experimental data in this paper was acquired using a subsonic wind tunnel test facility as shown in Fig. 2. A complete design and performance description can be found in Schobeiri and Pardivala (1992). As a result, only a brief description of the facility is given in this section.

The facility consists of a large centrifugal fan, settling chamber, nozzle, wake generator, and curved test section. By using a throttle mechanism at the exit of the fan, the velocity at the inlet of the test section was set at $12 \mathrm{~m} / \mathrm{s}$. Table I gives the rest of the inlet flow conditions. Just downstream of the fan, a Prandtl probe in the straight pipe can sense any velocity fluctuations that might arise due to fluctuations in fan speed. Downstream of the diffuser is the settling chamber constructed of three rectangular ducts that are $750 \mathrm{~mm}$ long, $1200 \mathrm{~mm}$ wide, and $820 \mathrm{~mm}$ high. Four stainless steel screens and one honeycomb flow straightener are located throughout the chamber to control the turbulence and uniformity of the flow. A nozzle with a $4: 1$ area ratio is attached to the exit of the settling chamber to accelerate smoothly the flow to the wake generator. The four screens, honeycomb flow straightener, and nozzle produce a freestream turbulence intensity of approximately $1.2 \%$ at the inlet of the test section.

The squirrel-cage-type wake generator generates the unsteady flow condition present at the inlet of the test section. The wake generator consists of two parallel, rotating, circular disks in which circular rods or cylinders can be arranged circumferentially. Stationary disks cover the parallel disks to eliminate the undesirable secondary shear flows generated by the rotating disks. Each rod generates a primary and secondary wake per revolution. The secondary wake serves as the background turbulence generator, whereas the primary wake is responsible for generating the periodic unsteady flow. To determine the effect of wake passing frequency

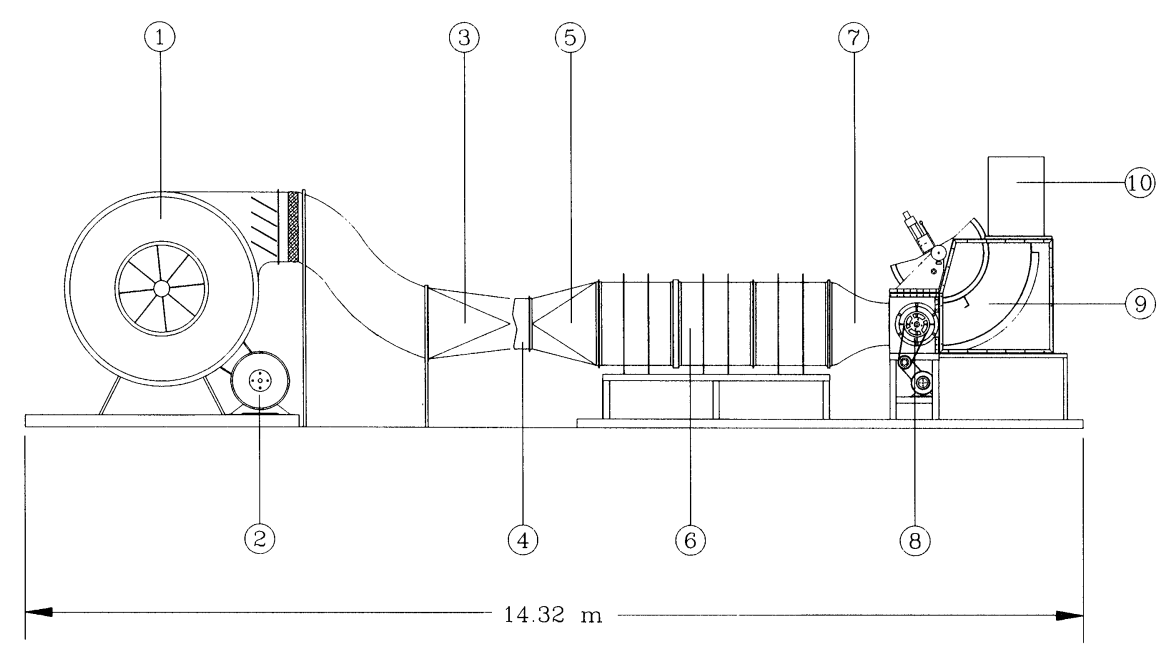

FIGURE 2 Overall layout of the test facility: 1. Fan, 2. Motor, 3. Transition duct, 4. Straight pipe, 5. Diffuser, 6. Settling Chamber, 7. Nozzle, 8. Wake generator, 9. Test section, 10. Exit duct. 
TABLE I Specifications of inlet flow and wake generator characteristics

\begin{tabular}{lclc}
\hline Parameters & \multicolumn{1}{c}{ Values } & \multicolumn{1}{c}{ Parameters } & Values \\
\hline Curved plate arc length & $s_{0}=690 \mathrm{~mm}$ & Nozzle exit turbulent intensity & $\mathrm{Tu}=1.20 \%$ \\
Nozzle exit height & $h_{\mathrm{n}}=420.00 \mathrm{~mm}$ & Nozzle exit width & $w=593.00 \mathrm{~mm}$ \\
Curved plate Reynolds number & $\mathrm{Re}_{\mathrm{s} 0}=0.56 \times 10^{6}$ & Rod diameter & $d_{\mathrm{R}}=2 \mathrm{~mm}$ \\
Steady reference (no rods) & $s_{\mathrm{R}}=0 \mathrm{~mm}$ & $\Omega$-parameter steady case & $\Omega=0.0$ \\
Set 1 rod spacing & $s_{\mathrm{R}}=314.0 \mathrm{~mm}$ & $\Omega$-parameter for set 1 & $\Omega=1.033$ \\
Set 2 rod spacing & $s_{\mathrm{R}}=188.4 \mathrm{~mm}$ & $\Omega$-parameter for set 2 & $\Omega=1.725$ \\
Set 3 rod spacing & $s_{\mathrm{R}}=94.2 \mathrm{~mm}$ & $\Omega$-parameter for set 3 & $\Omega=3.443$ \\
Set 4 rod spacing & $s_{\mathrm{R}}=62.8 \mathrm{~mm}$ & $\Omega$-parameter for set 4 & $\Omega=5.166$ \\
No. of rods in set 1 & $n_{\mathrm{R}}=3$ & No. of rods in set 2 & $n_{\mathrm{R}}=5$ \\
No. of rods in set 3 & $n_{\mathrm{R}}=10$ & No. of rods in set 4 & $n_{\mathrm{R}}=15$ \\
Distance between the rod and & $x_{\mathrm{Ple}}=252.9 \mathrm{~mm}$ & Distance/rod diameter ratio & $x_{\mathrm{Ple}} / d_{\mathrm{R}}=126.5$ \\
the plate leading edge & & & \\
\hline
\end{tabular}

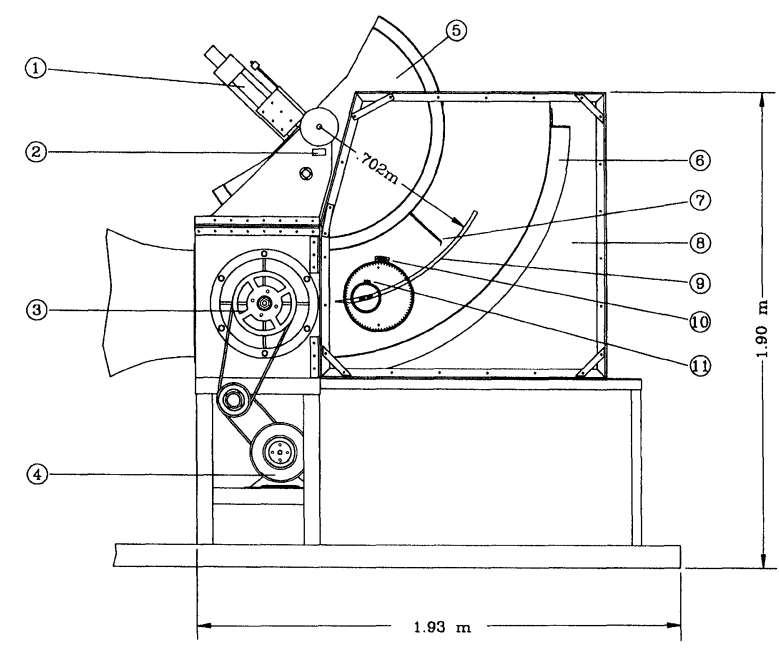

FIGURE 3 Test Section: 1. Traversing system, 2. Nozzle, 3. Wake generator, 4. Electric motor, 5. Convex wall, 6. Concave wall, 7. Hot-wire probe, 8. Plexiglas wall, 9. Curved plate for aerodynamic measurements, 10. Small vernier, 11. Large vernier.

on boundary layer transition, the wake generator was run with five different rod sets (see Table I). The wake generator rotates counterclockwise from the point of view of Fig. 3 to simulate the rotor-stator wake interaction within a turbomachinery stage. A fiber-optic sensor measures the angular frequency of the wake generator. The unsteady parameter $\Omega$ appropriately characterizes the unsteady character of the wake flow produced by the wake generator defined as $\Omega=\left(C_{\mathrm{D}} s_{0} / s_{\mathrm{R}}\right) / \phi$, where $s_{0} / s_{\mathrm{R}}$ is the ratio of the arc length of the plate $s_{0}$ and the spacing between the rods $s_{\mathrm{R}}, \phi$ is the ratio of the inlet velocity $U_{\text {in }}$ and the circumferential velocity of the wake generator $U_{\mathrm{w}}$, and $C_{\mathrm{D}}$ is the drag coefficient of the wake generating rod. Experimental investigations by Schobeiri et al. (1996) show that the wake drag coefficient is approximated as $C_{\mathrm{D}}=1.0$ for a distance/diameter ratio of $x_{\mathrm{Ple}} / d_{R}=126.5$ (see Table I). The parameter $\Omega$ is related to the Strouhal number introduced by Speidel (1957) and taken over by several researchers. However, the Strouhal number does not account for turbomachinery stage characteristics and the wake decay process characterized by the drag coefficient $C_{\mathrm{D}}$. The values of $\Omega$ cover a typical range of a turbomachine and are specified in Table I.

The test section in Fig. 3 consists of a top convex wall, a lower concave wall, and two vertical Plexiglas side walls. The top convex wall supports a linear traversing system and can rotate about its center of curvature, which permits the streamwise and radial positioning of the hot-wire probes and thermocouple. The curved plate is mounted between the two Plexiglas side walls. A positioning system, consisting of two angular verniers and a disk with the curved plate mounted eccentric to the center (Fig. 3), can precisely vary its axial and angular position. This positioning system allows variation of the pressure gradient and the fine adjustment of the leading edge position to avoid the start of separation bubbles. The plate's position is accurately determined by two angular verniers found on one Plexiglas wall. 
This investigation used two distinct curved plates to simulate the pressure surface of a turbine blade. The first was an aluminum curved plate and the second a heat transfer curved plate with the same concave dimensions as the aluminum plate. Boundary layer measurements were taken on both the aluminum curved and heat transfer plates (concave surfaces only) and heat transfer measurement were taken on both surfaces of the latter. The aluminum curved plate (Fig. 3) was $593.0 \mathrm{~mm}$ wide, with an arc length of $690.0 \mathrm{~mm}$, a radius of curvature of $702.5 \mathrm{~mm}$, a leading edge radius of $1.0 \mathrm{~mm}$, and a thickness of $15.0 \mathrm{~mm}$. This plate was mounted midheight in the test section and positioned with the angular verniers on the test section to achieve a zero pressure gradient on the concave surface. Boundary layer measurements were taken on the concave surface for $\Omega=0.0,1.033,1.725,3.443$, and 5.166 using a TSI single-wire probe with a $4-\mu \mathrm{m}$ tungsten filament. The probe was mounted on a computercontrolled linear traversing system. The traversing system, shown in Fig. 3, traverses in increments of $2.5 \mu \mathrm{m}$, which is useful in measuring the laminar sublayer. To capture most of the transition onset, the plate was traversed in the longitudinal direction in $2^{\circ}$ steps until $50 \%$ of the plate was reached. The next $25 \%$ of the plate was traversed in $3^{\circ}$ increments and the last quarter was traversed in $5^{\circ}$ increments. For each streamwise position, the boundary layer measurements were started $0.1 \mathrm{~mm}$ above the surface of the plate and terminated $10.0 \mathrm{~mm}$ above the curved plate. The same procedure was used to take aerodynamic measurements for the 0 and $3 \mathrm{rod}$ cases on the heat transfer plate. Measurements were taken on the heat transfer plate to insure that the new plate provided a similar response so that comparisons could be made between the boundary layer and heat transfer measurements. This was accomplished with the steady case, and the 3 rod case was performed to acquire more data on the effect of wake passing frequency. Steady $\mathrm{X}$-wire measurements were also performed $1^{\circ}$ directly upstream of the heat transfer plate to determine the characteristics of the flow before contact with the plate. The traverse started $50 \mathrm{~mm}$ above the bottom concave wall and stopped $50 \mathrm{~mm}$ below the top convex wall.

Like the aluminum curved plate, the heat transfer plate was positioned mid-height in the test section and angled so that the concave surface was exposed to a zero pressure gradient. The heat transfer plate has the same dimensions as the aluminum plate, with the exception being the $5 \mathrm{~mm}$ leading edge radius and the radius of curvature for the first $3 \%$ of the convex surface. The heat transfer plate is constructed of $1 \mathrm{~mm}$ thick Bakelite sheets laid over several Bakelite ribs. High resistant insulation fills the air pockets between the ribs to reduce the heat loss due to conduction. Two copper bus bars found at the trailing edge of the curved plate are connected to 10-gauge copper wire attached to a DC power supply. Figure 4 shows the external surface of the plate. As shown, a double-sided, acrylic based, high temperature adhesive sheet with a $0.1 \mathrm{~mm}$ thickness and $183 \mathrm{~mm}$ width is applied to the Bakelite surface from the concave surface trailing edge to the convex surface trailing edge. A $0.0254 \mathrm{~mm}$ thick sheet of Inconel 600 foil is attached on top and tach welded to the copper bus bars at the trailing edge. Applied to the surface of the foil is a thin coat of black paint to absorb the incoming radiation and reduce its refraction. The final layer is a thin coat of cholesteric liquid crystals mixed with a permanent binder. The purpose of the permanent binder is to protect the liquid crystals from ultraviolet light and atmospheric contaminants so they do not deteriorate as rapidly. Grid lines in $10 \mathrm{~mm}$ increments start at the leading edge and are found on top of the liquid crystals on both surfaces to show the position of the yellow band.

\section{INSTRUMENTATION, DATA ACQUISITION AND REDUCTION}

\subsection{Boundary Layer Measurements}

Data acquisition is controlled by a $386,40-\mathrm{MHz}$ personal computer connected to a 12 bit, 16 channel A/D board with simultaneous sample and hold. 

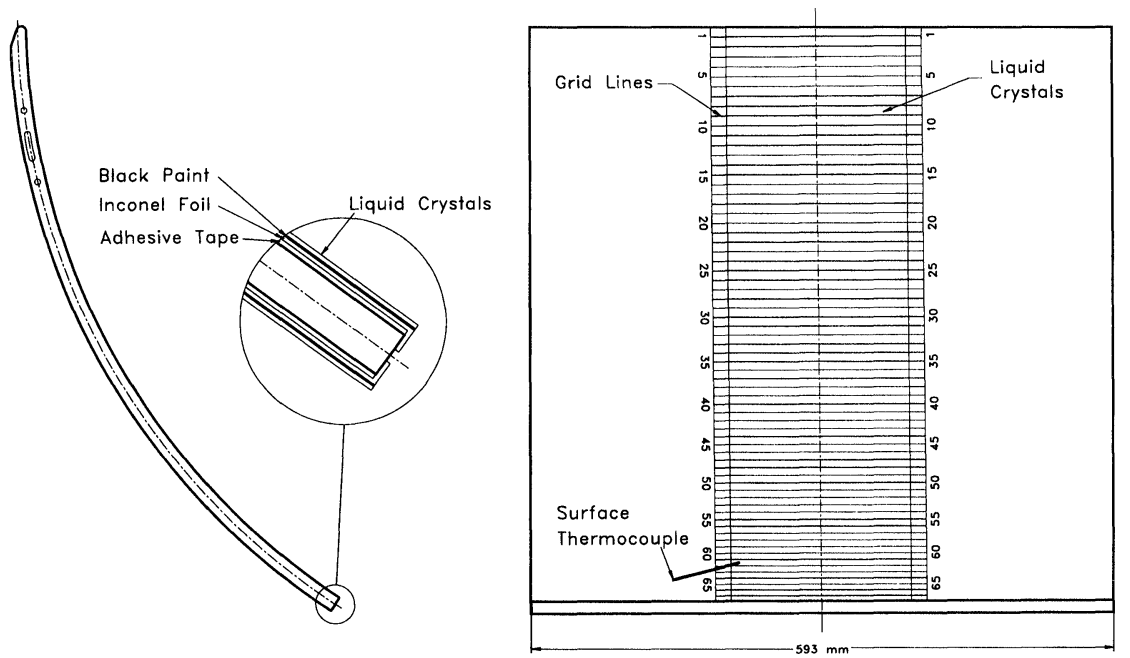

FIGURE 4 External view of the heat transfer curved plate showing grid lines, liquid crystals, and surface thermocouple.

A constant temperature hot-wire anemometer system (TSI-IFA 100) connected to the first channel of the A/D board supplies the instantaneous velocity signal. Based on many spectral measurements within the wake, the low pass filter of the signal conditioner was set to $20 \mathrm{kHz}$. A custom designed single-wire probe with a $4-\mu \mathrm{m}$ tungsten filament was the input to the flow analyzer for boundary layer measurements. For inlet velocity information, the data was collected with a specially designed $\mathrm{X}$-wire probe. These probes were calibrated with the method described in John and Schobeiri (1993). A T-type thermocouple mounted on the side of the test section found the air temperature.

The root means square value of the turbulent velocity fluctuation is obtained from the instantaneous and time-averaged velocity

$$
u=\sqrt{\frac{1}{N} \sum_{j=1}^{N}\left(U_{j}-\bar{U}\right)^{2}} .
$$

Besides time-averaged results, the unsteady data are ensemble-averaged with respect to the rotation period of the wake generator. Thus, the ensembleaveraged results calculated over the 300 revolutions show primary wake passes equal to the number of rods. The ensemble-averaged velocity is given by

$$
\left\langle U_{i}\left(t_{i}\right)\right\rangle=\frac{1}{N} \sum_{j=1}^{N} U_{i j}\left(t_{i}\right)
$$

A triggering system that measures each revolution and starts data collection simultaneously for each revolution makes the ensemble-averaging possible. The ensemble-averaged turbulence intensity is calculated from

$$
\begin{aligned}
\left\langle T u_{i}\left(t_{i}\right)\right\rangle & =\frac{\left\langle u_{i}\left(t_{i}\right)\right\rangle}{U_{\text {ref }}} \\
& =\frac{1}{U_{\text {ref }}} \sqrt{\frac{1}{N} \sum_{j=1}^{N}\left(U_{i j}\left(t_{i}\right)-\left\langle U_{i}\left(t_{i}\right)\right\rangle\right)^{2}}
\end{aligned}
$$

where $j=1,2, \ldots, N$, and $N$ are the total number of periods $(N=300)$ and $I=1,2, \ldots, M$, where $M$ is the number of samples taken per period $(M=2048) . U_{\text {ref }}$ is the reference velocity, which is the freestream velocity at a particular streamwise position. 


\subsection{Heat Transfer Measurements}

Several researches (Simonich and Moffat, 1984; Crane and Sabzvari, 1989; You et al., 1989, and Schobeiri et al., 1991) have used the liquid crystal measurement technique to determine the heat transfer coefficient distribution along the surface of a curved plate. However, none used the scheme with unsteady wakes. Hippensteele et al. (1983) applied liquid crystals to turbomachinery by developing a convenient method of using liquid crystals with a composite heater sheet to determine the local heat transfer coefficient distribution on both sides of a turbine blade. The original heater sheet consisted of a plastic with a carbon impregnated coating that gave a heat transfer coefficient error of $\pm 6.2 \%$. You et al. and Schobeiri et al. used Inconel 600 foil as the heater sheet. Russell et al. (1993) proved that the Inconel 600 foil was a more uniform heater sheet by determining that the error for the heat transfer coefficient was approximately $\pm 3.7 \%$. Therefore, the heater sheet in this investigation is Inconel 600 .

A Sorenson DC 40-70 power supply, capable of $40 \mathrm{~V}$ at $70 \mathrm{~A}$, heats the heat transfer plate. Due to the panel meters in the power supply not having sufficient resolution, the voltage is recorded using a Fluke 87 multimeter connected to the terminals of the power supply. The current is also measured with a Fluke 87 multimeter, with the multimeter connected to a $50 \mathrm{mV}-50 \mathrm{~mA}$ shunt placed in series with the heat transfer plate. The freestream air temperature is recorded with a specially designed E-type thermocouple that fits in the probe traversing system. The thermocouple is positioned high enough from the curved plate so that it is not affected by the velocity or thermal boundary layer. Another E-type thermocouple mounted on the surface of the heat transfer plate calibrates the color of the liquid crystals under no flow conditions. As with the boundary layer investigation, the personal computer controls the wake generator.

The yellow band of the liquid crystal is calibrated for temperature at the beginning of each wake passing frequency test. The yellow band is used for measurements because it occurs over the narrowest temperature band and has good uniformity (Hippensteele et al., 1985). The calibration consists of adjusting the power from the power supply until the yellow band is directly on top of the surface mounted thermocouple. The temperature is recorded once steady state has been reached. This calibration is done under no flow conditions and repeated several times. The yellow band temperature was approximately $47.5^{\circ} \mathrm{C}$ for each calibration performed. Following calibration, the wind tunnel is started, the wake generator set, and the power supply adjusted so that the yellow band is at the leading edge of the curved plate. In this configuration, the facility runs for $2 \mathrm{~h}$ so that the temperature inside the curved plate can reach equilibrium. This helps reduce the losses due to conduction and allows the location of the yellow band to be accurately determined. To check whether steady state has been reached, the surface thermocouple is constantly monitored to ensure that the foil temperature is not fluctuating.

After $2 \mathrm{~h}$, the voltage and current supplied to the Inconel foil are obtained from the multimeters and recorded. The location of the yellow band at the centerline of the curved plate on the convex and concave surfaces is read from the appropriate set of grid lines. These values, along with freestream air temperature, atmospheric pressure, rpm, number of rods, and foil temperature are recorded. The power is then reduced to move the yellow band away from the leading edge in $10 \mathrm{~mm}$ increments, and a $30 \mathrm{~min}$ period is allowed for steady state operation to be achieved before these quantities are rerecorded. This process continues until the full longitudinal length of the plate for both surfaces is completely mapped. Once all the data are taken, the information is transferred to the computer for data reduction. This process is the same for all wake passing frequencies.

The collected data are reduced based upon a heat flux analysis that entails determining all the energy losses on a flux basis and subtracting them from the heat flux of the Inconel foil. This leaves the convective portion of the energy equation and, 
from this, the heat transfer coefficient can be obtained with the following equation:

$$
h=\frac{Q_{\mathrm{conv}}}{\left(T_{\mathrm{yl}}-T_{\infty}\right)}
$$

where $T_{\mathrm{yl}}$ is the temperature of the yellow band and $T_{\infty}$ is the freestream air temperature. $Q_{\text {conv }}$ is the convective portion of the energy equation per unit area and is defined by

$$
Q_{\mathrm{conv}}=Q_{\mathrm{foil}}-Q_{\mathrm{rad}}-Q_{\mathrm{cond}}
$$

where $Q_{\text {foil }}$ is the heat flux of the Inconel foil and $Q_{\text {rad }}$ is the radiation heat flux emitting from the surface of the liquid crystals. These two quantities are given by

$$
Q_{\text {foil }}=\frac{V I}{A_{\text {foil }}}
$$

and

$$
Q_{\mathrm{rad}}=\epsilon \sigma\left(T_{\mathrm{yl}}^{4}-T_{\infty}^{4}\right)
$$

where $V$ and $I$ are the voltage and current supplied from the power supply, respectively, and $A_{\text {foil }}$ is equal to the total heat surface area of the Inconel 600 foil. For the radiation term, $\epsilon$ is the emissivity of the liquid crystals and has a value of 0.85 and $\sigma$ is the Stefan--Boltzmann constant. The radiation reflected back from the top aluminum wall was less than $2 \%$ of the input power and was neglected as a result. The third loss, the conduction losses, was negligible based upon a two-dimensional finite difference nodal analysis method on a slice of the curved heat transfer plate.

\section{RESULTS AND DISCUSSION}

\subsection{Aerodynamics}

To describe the state of the flow immediately upstream of the curved plate, the results of the inlet velocity measurements are presented first. Single wire measurement results are then discussed to describe the boundary layer transition process that occurs due to unsteady periodic wakes. The heat transfer results are presented last. To ensure that the concave portion of the curved plate was subjected to a zero pressure gradient, the freestream velocity was measured. The measurement showed a zero pressure gradient over the entire curved plate.

\section{Time-averaged Non-dimensional Mean Velocity}

Figure 5(a) and (b) present the non-dimensional time-averaged velocity distributions at three different longitudinal locations for $\Omega=0$ and 3.443. A wall correction scheme was implemented for all cases for $y^{+}<6$, which is necessary when measuring with a hot-wire probe in the near wall region. The steady case $(\Omega=0.0)$ appears first and serves as
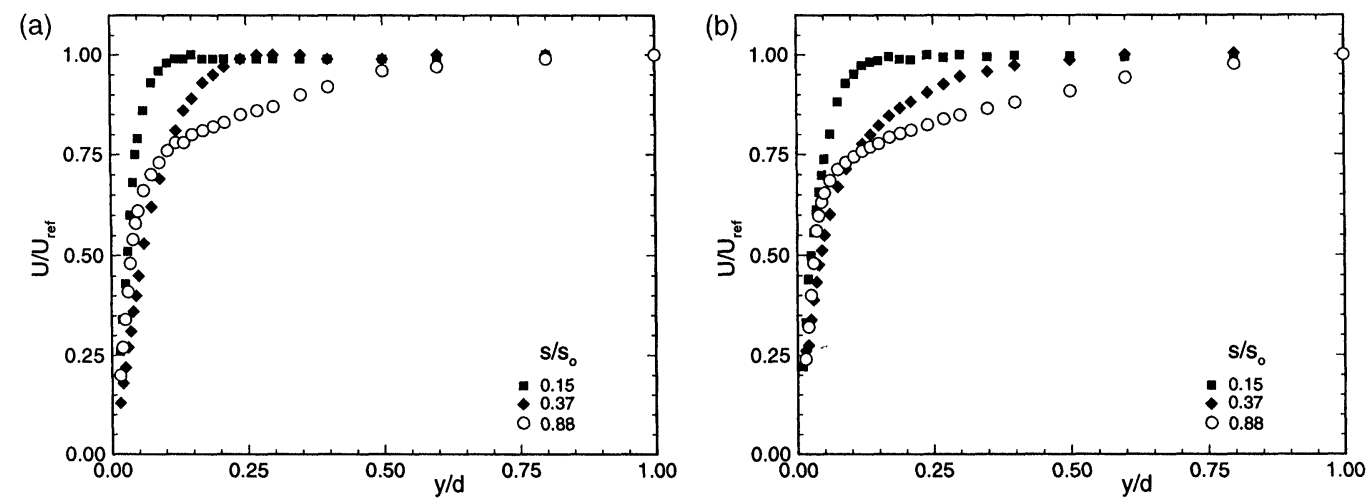

FIGURE 5 Non-dimensional mean velocity at three different $s / s_{0}$ locations for (a) $\Omega=0.000$ and (b) $\Omega=3.443$. 
a reference for the unsteady cases. In Fig. 5(a), at $s / s_{0}=0.15$ for $\Omega=0.0$, the non-dimensional velocity diagram shows the edge of the boundary layer to be around $y / d=0.06$. The high velocity gradient and small boundary layer thickness suggest that the state of the boundary layer is laminar. Farther downstream at $s / s_{0}=0.37$, the velocity profile suggests a transitional character. At this location, the edge of the boundary layer is around $y / d=0.25$. Finally, toward the trailing edge of the plate, $s / s_{0}=$ 0.88 , the shape of the non-dimensional velocity profile approaches almost a typical turbulent shape with an increased turbulence activity inside the boundary layer. At this point, the boundary layer has grown considerably, indicating that the boundary layer tends to become fully turbulent. These profiles clearly show that the boundary layer is undergoing a transition process. Although these profiles give a good description of the boundary layer development, they are not descriptive enough to give the state of the boundary layer. Figure 5(b) gives the non-dimensional velocity distributions for 3.443 (10 rods). This figure and the one for $\Omega=$ 1.033 ( 3 rods) show the same behavior as the steady case. However, it was found that the boundary layer thickness grows faster for higher values of $\Omega$, which is an indication that transition occurs sooner for increasing wake passing frequency. Besides showing that the velocity distribution changes during the transition process and that the location of the transition region is dependent upon the wake passing frequency, the time-averaged velocity distributions do not show any further details regarding the effect of the wakes upon the boundary layer flow. The following unsteady flow investigations provide detailed insight into the boundary layer transition process.

\section{Instantaneous Velocity Traces}

Instantaneous velocity, $U$, as a function of time is plotted in Fig. 6(a)-(d) for $\Omega=0.0,1.033,3.443$, and 5.166 at $y=0.3 \mathrm{~mm}$ above the concave surface of the curved plate for four streamwise locations. The total time of $200 \mathrm{~ms}$ corresponds to one revolution of the wake generator at $300 \mathrm{rpm}$. Figure 6(a), which corresponds to $\Omega=0.0$ (no rods), shows that the velocity at $s / s_{0}=0.04$ is smooth with a magnitude of around $10 \mathrm{~m} / \mathrm{s}$, which shows that the boundary layer is thin since the velocity is close to the potential flow velocity. Small disturbances appear farther downstream as two-dimensional Tollmien-Schlichting (TS) waves. These disturbances continue to amplify into large fluctuations $\left(s / s_{0}=0.48\right)$ and finally develop into turbulent spots that can be seen in the profile at $s / s_{0}=0.48$. The turbulent spots continue to grow and convect downstream, where they coalesce into a fully stochastic developed turbulent boundary layer exhibited at $s / s_{0}=0.88$.

As this process is occurring, the velocity is continually decreasing as shown by the traces, which is the result of the boundary layer growth. The streamwise location where the turbulent spots start to develop is taken as the start of boundary layer transition. Figure 6(b) shows the instantaneous velocity traces for $\Omega=1.033$ (3 rods). As shown, three wakes are present due to $200 \mathrm{~ms}$ being equivalent to one revolution of the wake generator. The secondary wakes have already decayed to the point where they are not distinguishable. In effect, they have already mixed with the flow contributing to a higher freestream turbulence level. At $s / s_{0}=0.04$, the velocity is very smooth between the wakes, which is characteristic of a laminar boundary layer. As with the steady case, small disturbances in the form of TS waves appear $\left(s / s_{0}=0.26\right)$ and continue to grow to form turbulent spots downstream $\left(s / s_{0}=0.48\right)$. At $s / s_{0}=0.88$, the turbulent spots have coalesced together generating a fully turbulent boundary layer where no wakes are distinguishable. Figure 6(c) exhibits a similar trend for $\Omega=$ 3.443 (10 rods). However, this shows that the TS waves observed between the wakes at lower $s / s_{0}$ values for $\Omega=1.033$ ( 3 rods) are about to be bypassed. This marks the beginning of bypass transition.

The $\Omega=5.166$ (15 rod) case reveals a different flow picture than the lower wake passing frequencies. The velocity traces for this case can be found in Fig. 6(d). At $s / s_{0}=0.04$, the wakes are not visible 
(a)

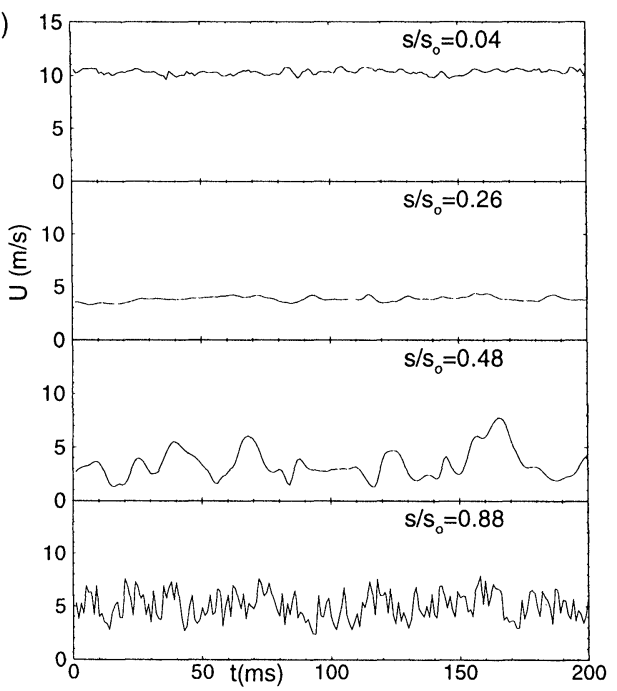

(b)

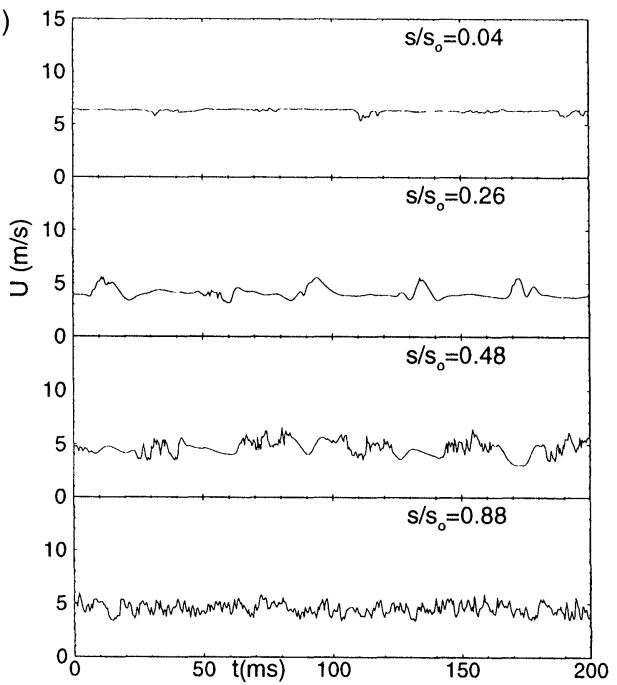

(c)

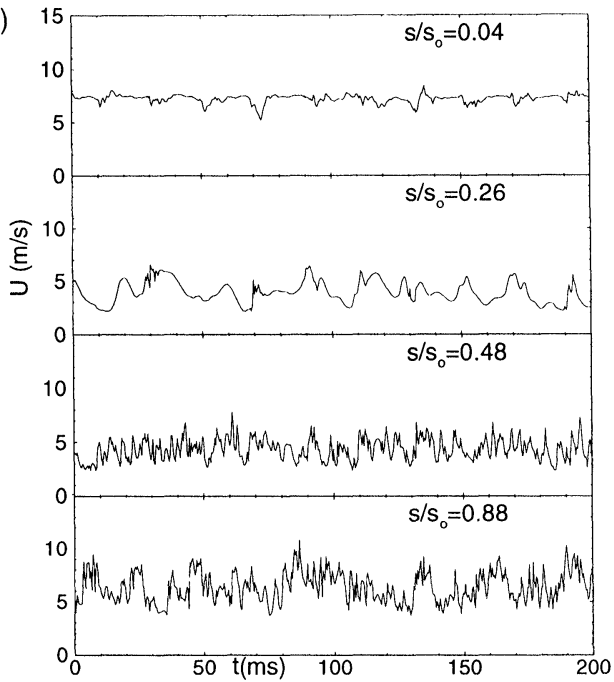

(d)

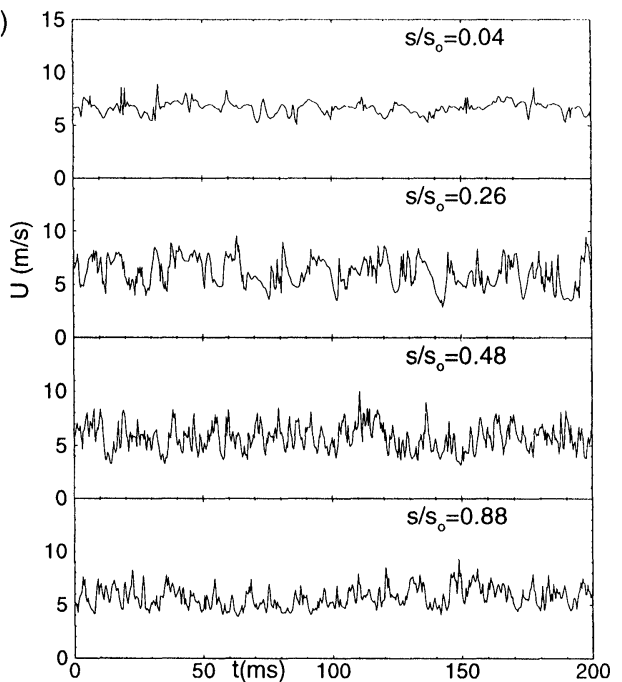

FIGURE 6 Instantaneous velocity traces for four different $s / s_{0}$ location for (a) $\Omega=0.000$, (b) $\Omega=1.033$, (c) $\Omega=3.443$, and (d) $\Omega=5.166$ at $y=0.3 \mathrm{~mm}$.

due to a strong wake interaction. Farther downstream at $s / s_{0}=0.26$, turbulent spots are present that coalesce to form a fully turbulent boundary layer. The flow is completely turbulent at $s / s_{0}=$ 0.48. Due to the small wake spacing and intense mixing of the wakes, it appears that the TS mode of instability has been completely bypassed. It is evident from these traces that the combined effect of increased wake passing frequency and wake mixing increases the freestream turbulence. This causes an intense turbulent activity within the boundary layer toward the leading edge of the curved plate. This means that the onset of transition has shifted toward the leading edge of the curved plate.

\section{Time-averaged Turbulent Intensity Contours}

Further details on boundary layer transition and development can be obtained from the timeaveraged turbulence intensity contours presented in Fig. 7(a)-(e). For each wake passing frequency, the turbulence intensity was time-averaged in the 
(a)

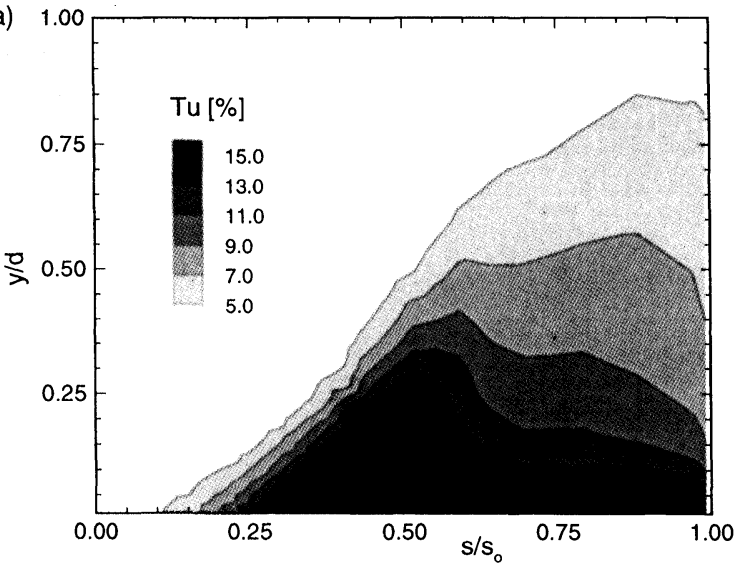

(b)

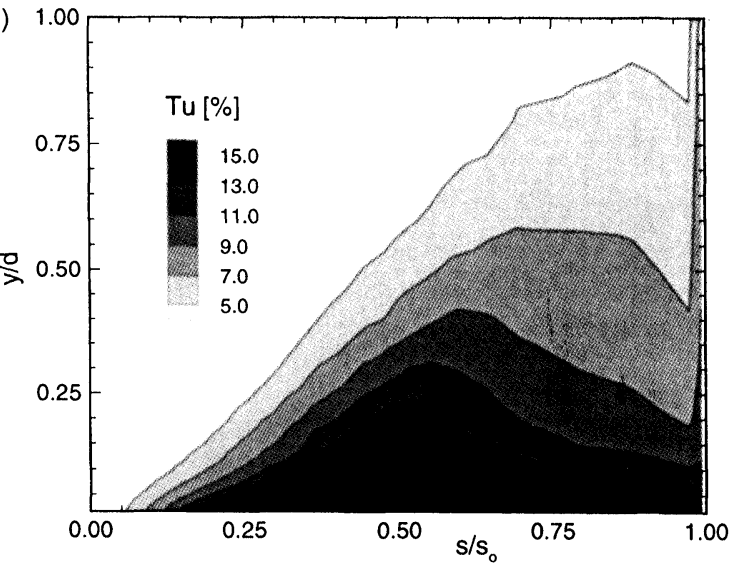

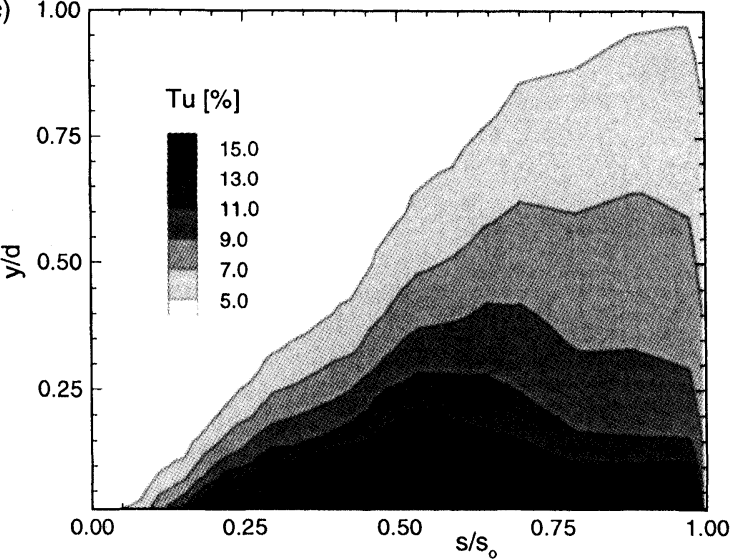

(d)

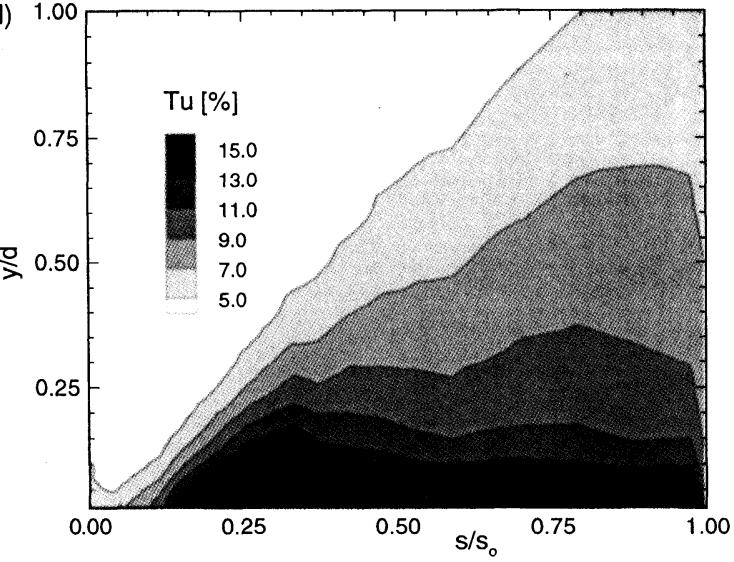

(e)

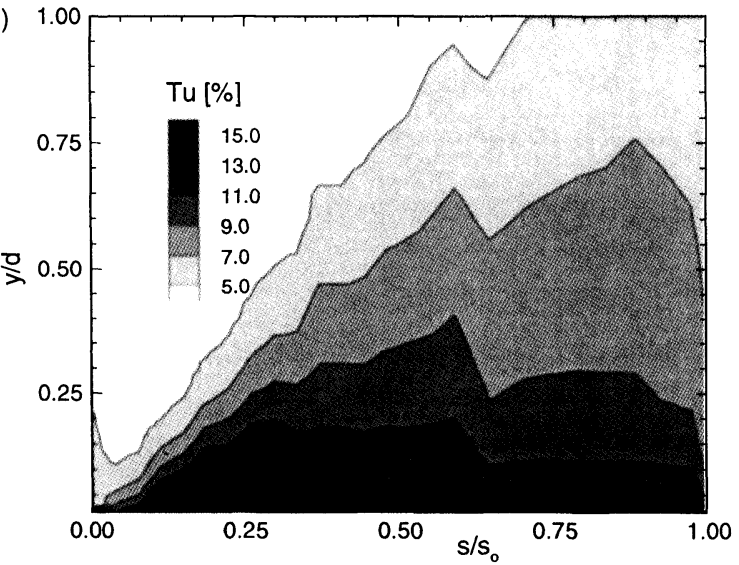

FIGURE 7 Time-averaged turbulence intensity contours for (a) $\Omega=0.000$, (b) $\Omega=1.033$, (c) $\Omega=1.725$, (d) $\Omega=3.443$, and (e) $\Omega=5.166$ 
lateral direction, $y / d$ where $d=10 \mathrm{~mm}$, for different streamwise positions. Figure 7 (a) shows a high turbulent intensity core $(>15 \%)$ for $\Omega=0.0$ in the near wall region for more than $75 \%$ of the plate with its center located at $s / s_{0}=0.51$ and with a lateral extension of $y / d=0.25$. At $\Omega=1.033$, the core shifts toward the leading edge, indicating an earlier beginning of the transition process, and the lateral extension reduces to $y / d=0.17$. This reduction is due to the calming effect caused by wake impingement on the boundary layer flow. Schobeiri and Radke (1994), Orth (1992), and Pfeil and Herbst (1979) discussed this phenomenon extensively. Figure 7(c and d) shows a further reducing of the wake spacing and increasing the wake passing frequency to $\Omega=3.443$. This shifts the high turbulent intensity core more toward the leading edge and further extends the becalmed regions thus reducing the lateral extension of the core to $y / d=$ 0.12 . For $\Omega=5.166$, Fig. 7(e) shows the lateral extension of the core has diminished to $y / d=0.08$ and the start of the turbulent core is at $s / s_{0}=0.08$ revealing the effect of unsteadiness as to cause earlier transition. Liu and Rodi (1992) also observed this trend. The shift in transition toward the leading edge of the curved plate due to the increase of unsteady wake parameter $\Omega$ has two causes. The first is that a higher impinging frequency hastens increased energy transfer to the boundary layer. The second is that the earlier mixing of the secondary wakes causes a rise in the freestream turbulence intensity (see Schobeiri et al., 1995a). The time-averaged data presented above gives a reasonably good picture of how the transition process occurs under the influence of periodic unsteady wakes.

\section{Ensemble-averaged Turbulence Intensity}

Figure 8(a)-(d) shows the ensemble-averaged reference turbulence intensity contours in the temporal-spatial domain at a wall distance of $y=$ $0.3 \mathrm{~mm}$ for each $\Omega$ case to obtain a detailed picture that reflects the physics of the unsteady boundary layer process. The reference velocity is equal to the velocity at $10 \mathrm{~mm}$ above the plate's surface for each streamwise position, with the data ensembleaveraged for 300 revolutions of the wake generator. Figure $8(\mathrm{a})(\Omega=1.033,3$ rods) shows three wakes that periodically disturb the boundary layer and produce high turbulence intensity cores (up to 15\%) and extended becalmed regions (less than 1\%). Compared with the steady case shown in Fig. 7(a), where the low turbulence intensity region extends up to $s / s_{0}=0.10$, the becalmed regions extend to $s / s_{0}=0.23$. Increasing $\Omega$ to 1.725 (5 rods, Fig. $8(\mathrm{~b})$ ) at $y=0.3 \mathrm{~mm}$ causes the lateral extension of the becalmed regions to diminish due to earlier mixing between the wakes. However, the longitudinal extension is still preserved.

By increasing $\Omega$ to 3.443 (10 rods, Fig. 8(c)) the becalmed regions become narrower and the slope of the wakes increases further. In addition, the high turbulent intensity core shifts forward indicating earlier transition. The turbulent intensity of the last $50 \%$ of the plate is extremely high at around $13 \%$ due to increased wake impingement and interaction. At the final value of $\Omega$ (15 rods, Fig. 8(d)), the becalmed regions become shorter and extend to only $s / s_{0}=0.15$. The core also shifts toward the leading edge and starts at around $s / s_{0}=0.20$. Unlike the 10 rod case $(\Omega=3.443)$, the turbulent intensity of the last $40 \%$ of the curved plate is around only $8 \%$ instead of $13 \%$. The reason for this is that the wakes have thoroughly mixed leading to finer turbulence distributions. Figure 8(a)-(d) presents a clear picture on the effect of periodic unsteady wakes on boundary layer transition. As previously mentioned, two factors cause the shifting of the transition process toward the leading edge of the plate. The first is an increase in the impinging frequency of the primary wakes. As the wakes convect downstream, the individual wake widths continually increase until they have reached approximately the size of the rod spacing. At this location, a mixing of the wake and the flow causes a highly turbulent flow with a turbulent intensity around $15 \%$. As the wake passing frequency increases, the wake interaction occurs earlier and introduces an excessive turbulent kinetic energy 
(a)

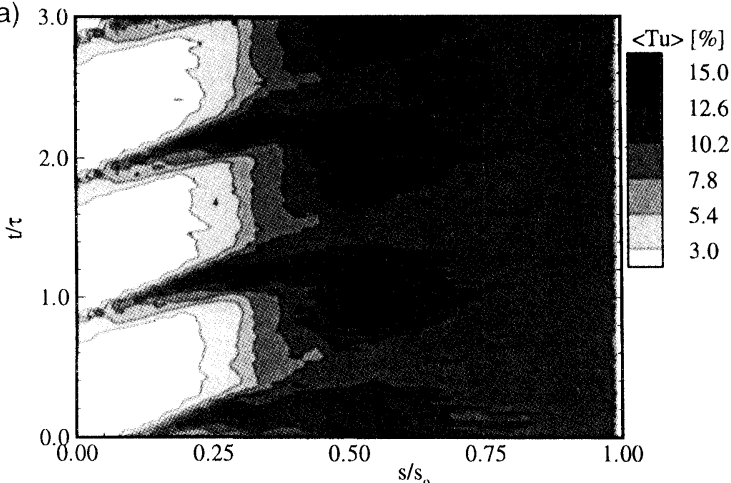

(c)

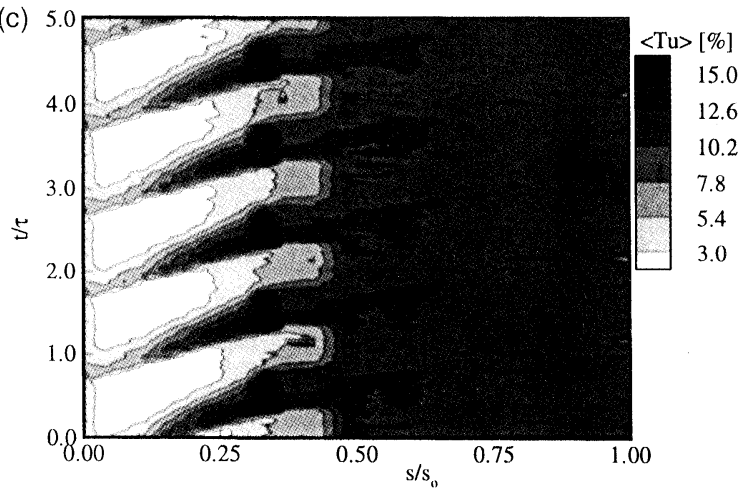

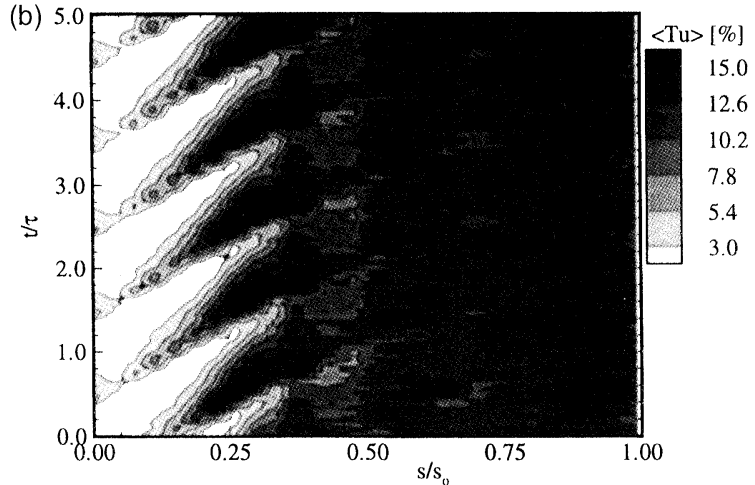

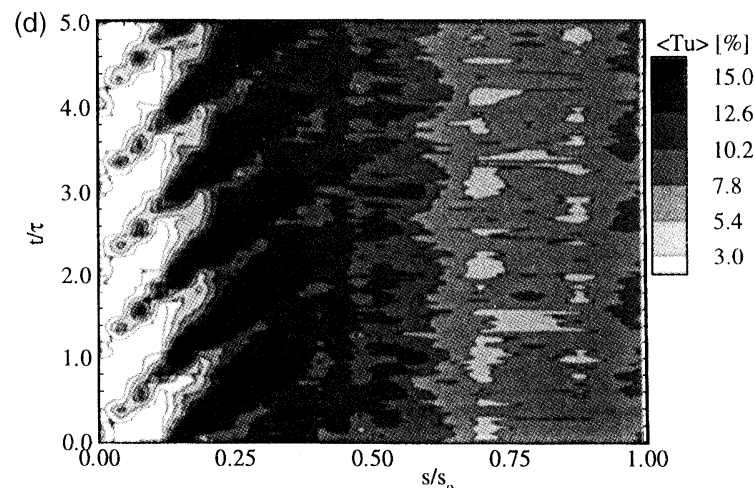

FIGURE 8 Ensemble-averaged reference turbulence intensity in the temporal-spatial domain at $y=0.3 \mathrm{~mm}$ above the plate for (a) $\Omega=1.033$, (b) $\Omega=1.725$, (c) $\Omega=3.443$, and (d) $\Omega=5.166$

transport to the boundary layer causing a shift of transition toward the leading edge (see Schobeiri et al., 1995a). The second factor is an earlier mixing of wakes due to the reduction of the wake spacing that causes a higher freestream turbulent intensity proven to contribute to the onset of boundary layer transition. A combination of these two factors determines the transition process as presented above.

\section{Intermittency Analysis}

Intermittency distribution to identify whether the flow is laminar or turbulent inside the boundary layer is calculated following the method of Hedley and Keffer (1974). Instantaneous velocities identify this intermittency distribution. Figure 9 gives representative plots of an ensemble-averaged velocity signal inside the boundary layer. Outside the

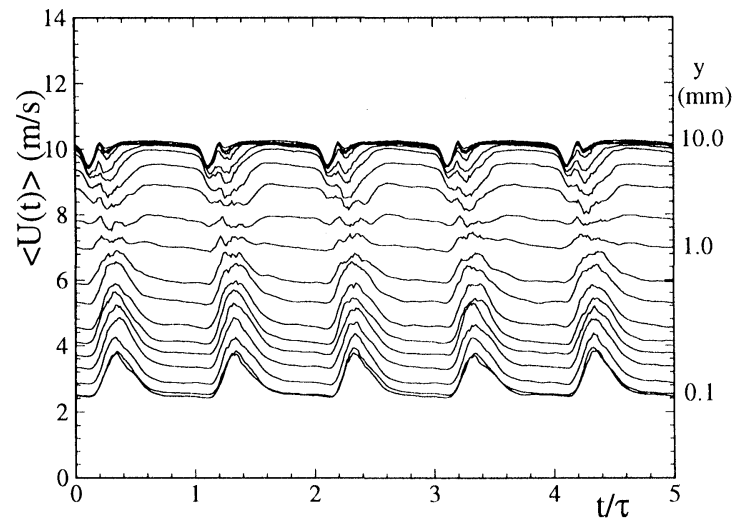

FIGURE 9 Ensemble-averaged velocity distribution as a function of non-dimensional time at different $y$-locations and $s / s_{0}=0.25$ for $\Omega=1.725$ (5 rods).

boundary layer $(y=10 \mathrm{~mm})$ are separated periodic wake regions in the freestream flow region. By moving the probe inside the boundary layer, the velocity is subjected to an increasing wall shear 
stress effect that causes deceleration of the undisturbed velocity and the wake flow. Furthermore, the damping effects of shear stress causes a phase lag between the undisturbed portion of the velocity and the wake. Moving farther toward the wall, the undisturbed velocity portion decelerates more rapidly than the vortical core of the wake. As a result, the flow pattern reverses. This phenomenon is due to the strong turbulence activities inside the boundary layer, which is magnified by the presence of the high turbulence vortical core of the wake. The instantaneous velocity is sensitized to increase its discriminatory capabilities between turbulent and non-turbulent parts of the signal. For this purpose, the second derivative of the velocity signal is used and squared for further analysis and called the detector function. The detector function $I(t)$ is a derivative of the velocity signal and will have zeros within fully turbulent flow. To avoid the influence of legitimate zeros, the signal is integrated over a short interval resulting in criterion function, $S(t)$. A threshold level $C$ is then applied to this criterion function to distinguish between the true turbulence and the signal noise:

$$
I(t)= \begin{cases}1 & \text { when } S(t) \geq C \\ 0 & \text { when } S(t)<C\end{cases}
$$

After applying the threshold level to the criterion function $S(t)$, the result is a random square wave with 0 's representing the laminar case and 1's representing the turbulent behavior of the boundary layer. This square wave is ensemble-averaged to get the ensemble-averaged intermittency as follows:

$$
\left\langle\gamma_{i}\left(t_{i}\right)\right\rangle=\frac{1}{n} \sum_{j=1}^{n} I_{i j}\left(t_{i}\right)
$$

where $n$ is the number of revolutions of the wake generator, for which the data is collected. For timeaveraged intermittency, $\left\langle\gamma_{i}\left(t_{i}\right)\right\rangle$ is integrated with respect to time to give

$$
\bar{\gamma}=\frac{1}{T} \int_{t=0}^{T}\left\langle\gamma_{i}\left(t_{i}\right)\right\rangle \mathrm{d} t .
$$

Figure 10(a) and (b) shows the intermittency distribution as a function of non-dimensional time for both the 3 and 10 rod cases. Similar plots are shown for other rod cases. Only the first two wakes are plotted for a better comparison of the effects of impinging wake frequency on the transition process. Intermittency is approximately equal to zero outside the wake region near the leading edge showing the non-turbulent behavior of the flow. The wake is represented by a thin strip with intermittency values near to one, typical of a turbulent flow. As these wakes pass through the channel, the boundary layer periodically switches from laminar to turbulent depending on their presence. Periodic passing of wakes affects the natural transition of the boundary layer resulting in wake-induced transition. The intermittency distributions in Fig. 10(a) and (b)

(a)

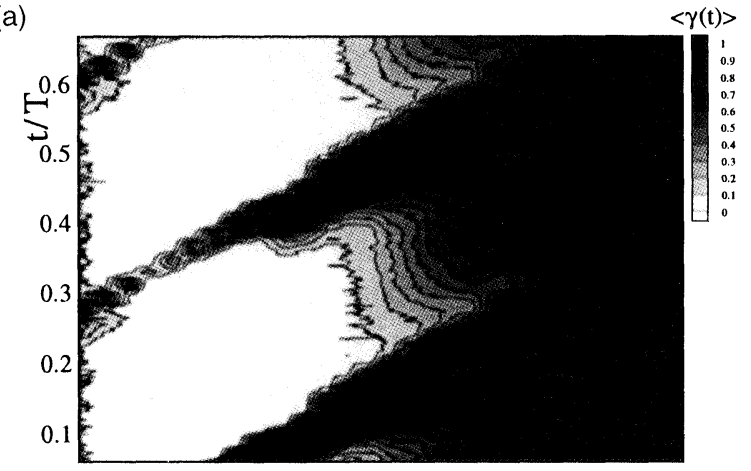

(b)

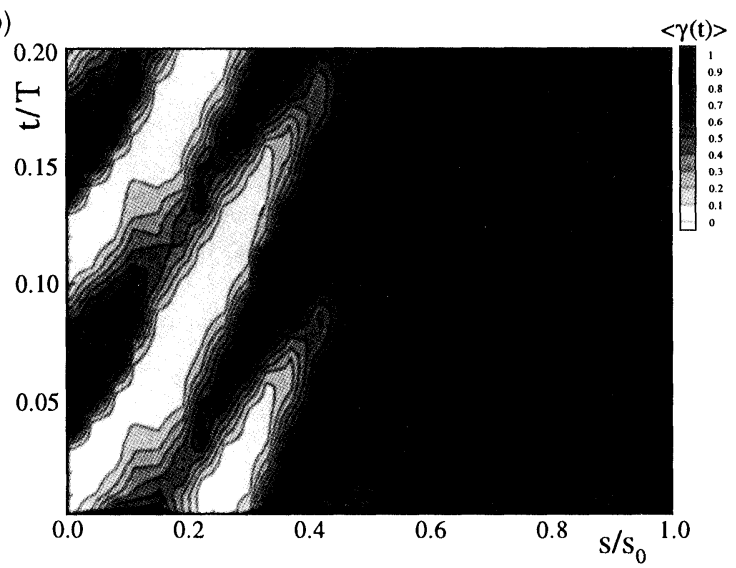

FIGURE 10 Contour plots of intermittency factor as a function of normalized axial distance $s / s_{0}$ for (a) $\Omega=1.033$ (3 rods) and (b) $\Omega=3.443$ (10 rods) 
clearly show the unsteady nature of the boundary layer transition. In this form, however, they cannot describe the complex unsteady transition process quantitatively. To establish the basic relations essential for a quantitative description of the unsteady boundary layer transition, we resort to the fundamental studies by Schobeiri et al. (1996) that deal with the physics of steady and unsteady wake development in a curved environment. These studies clearly show that the wake defect determines the turbulence structure of the steady and unsteady wake flow, which is a Gaussian function. Following the above studies, we define a dimensionless parameter

$$
\zeta=\frac{U_{\mathrm{w}} t}{b}=\frac{y}{b} \quad \text { with } b=\frac{1}{\sqrt{\pi}} \int_{-\infty}^{+\infty} \Gamma \mathrm{d} y
$$

that relates the passing time $t$ of a wake impinging on the plate surface with the wake passing velocity in the lateral direction $U_{\mathrm{w}}$ and the intermittency width $b$. The latter directly relates to the wake width introduced by Schobeiri and his co-workers (1996). In an analogous way to find the defect function, we define the relative intermittency function $\Gamma$ as:

$$
\Gamma=\frac{\left\langle\gamma_{i}\left(t_{i}\right)\right\rangle-\left\langle\gamma_{i}\left(t_{i}\right)\right\rangle_{\min }}{\left\langle\gamma_{i}\left(t_{i}\right)\right\rangle_{\max }-\left\langle\gamma_{i}\left(t_{i}\right)\right\rangle_{\min }} .
$$

In the above equation, $\left\langle\gamma_{i}\left(t_{i}\right)\right\rangle$ is the time dependent ensemble-averaged intermittency function, which determines the transitional nature of an unsteady boundary layer. The maximum intermittency $\left\langle\gamma_{i}\left(t_{i}\right)\right\rangle_{\max }$ exhibits the time dependent ensemble-averaged maximum intermittency value inside the wake vortical core. Finally, the minimum intermittency $\left\langle\gamma_{i}\left(t_{i}\right)\right\rangle_{\min }$ represents the ensembleaveraged minimum intermittency values outside the wake vortical core. Figure 11(a) and (b) shows the relative intermittency function $\Gamma$ for frequency values of $\Omega=1.033$ (3 rods) and 3.443 (10 rods), respectively, with the dimensionless longitudinal distance $s / s_{0}$ as the parameter. Similar results are obtained for other rod frequencies. The symbols represent the experimental data. For the reduced frequencies and longitudinal positions presented in these plots, the measured relative intermittency functions for wakes impinging on the plate surface closely follow a Gaussian distribution, given by

$$
\Gamma=\mathrm{e}^{-\zeta^{2}} .
$$

Here, $\zeta$ is the non-dimensionalized lateral length scale. Using this function as a valid intermittency relationship for zero-pressure gradient cases, the intermittency function $\left\langle\gamma_{i}\left(t_{i}\right)\right\rangle$ is determined if additional information is available on the minimum (a)

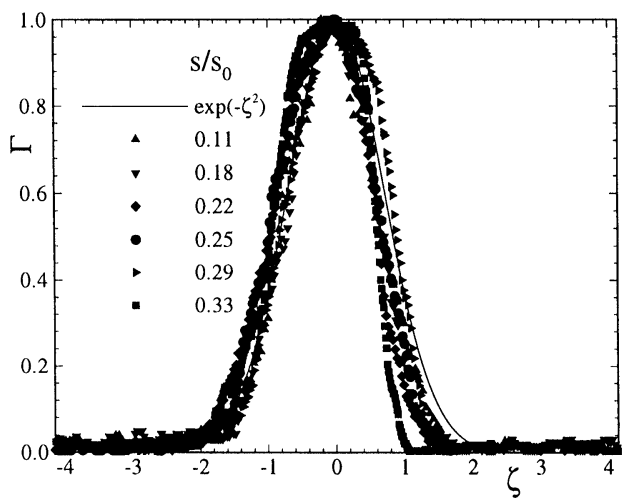

(b)

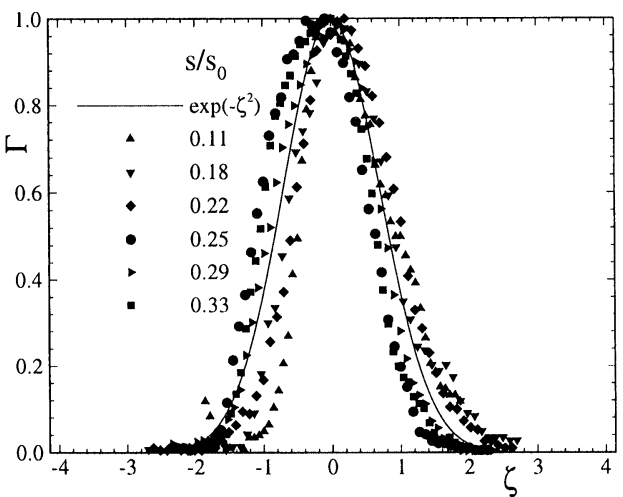

FIGURE 11 Relative intermittency as a function of non-dimensionalized lateral coordinate for (a) $\Omega=1.033$ (3 rods) and (b) $\Omega=3.443$ (10 rods). 
and maximum intermittency functions $\left\langle\gamma_{i}\left(t_{i}\right)\right\rangle_{\text {min }}$ and $\left\langle\gamma_{i}\left(t_{i}\right)\right\rangle_{\max }$. Figure 13 shows the distribution of $\left\langle\gamma_{i}\left(t_{i}\right)\right\rangle_{\min }$ and $\left\langle\gamma_{i}\left(t_{i}\right)\right\rangle_{\max }$ plotted in the streamwise direction for $\Omega=1.033$ ( 3 rods). The steady case (no rod case) in Fig. 12 serves as the basis of comparison for these maximum and minimum values. In the steady case, the intermittency starts to rise from zero at a streamwise Reynolds number $\operatorname{Re}_{x, \mathrm{~s}}=2 \times$ $10^{5}$ and gradually equals the unity corresponding to the fully turbulent state. This is typical of natural transition and follows the intermittency function introduced by Narasimha (1957). Figure 13 shows the distributions of maximum and minimum turbulence intermittencies $\left\langle\gamma_{i}\left(t_{i}\right)\right\rangle_{\min }$ and $\left\langle\gamma_{i}\left(t_{i}\right)\right\rangle_{\max }$ in the

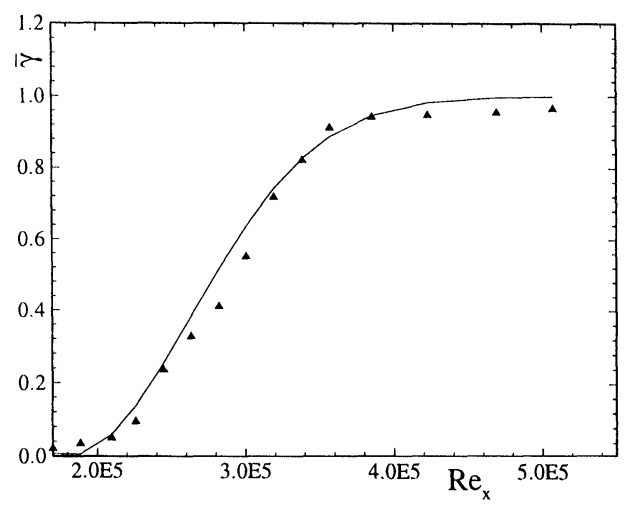

FIGURE 12 Intermittency as a function of $\mathrm{Re}_{x}$ for no-rod or steady case on the concave surface of the curved plate.

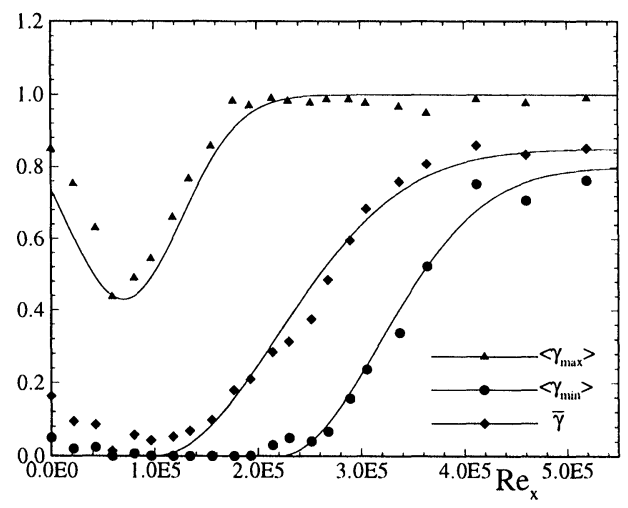

FIGURE 13 Maximum, minimum and time-averaged intermittency distributions as a function of streamwise Reynolds number for $\Omega=1.033$ ( 3 rods). streamwise direction. For each particular streamwise location on the blade surface with a streamwise Reynolds number, for example $\operatorname{Re}_{x, \mathrm{~s}}=1 \times 10^{5}$, two corresponding distinctively different intermittency states are periodically present. At this location, $\left\langle\gamma_{i}\left(t_{i}\right)\right\rangle_{\max }$ corresponds to the condition when the wake with a high turbulence intensity core impinges on the plate surface at a particular instant of time. Once the wake has passed over the surface, the same streamwise location is exposed to a low turbulence intensity flow regime with an intermittency state of $\left\langle\gamma_{i}\left(t_{i}\right)\right\rangle_{\min }$, where no wake is present. As seen, $\left\langle\gamma_{i}\left(t_{i}\right)\right\rangle_{\min }$ tends to follow the steady (no-wake) intermittency distribution shown in Fig. 12, with a gradual increase from an initial non-turbulent, state with a value of zero to a final state of 0.8 . This was expected, as $\left\langle\gamma_{i}\left(t_{i}\right)\right\rangle_{\min }$ is calculated outside the wake region where turbulence intensity is small. On the other hand, $\left\langle\gamma_{i}\left(t_{i}\right)\right\rangle_{\max }$ reveals a different behavior that needs to be further discussed. As Fig. 13 shows, the wake flow with an intermittency close to 1 impinges on the blade surface. By convecting downstream, its turbulent fluctuations undergo a strong damping by the wall shear stress forces. The process of damping continues until $\left\langle\gamma_{i}\left(t_{i}\right)\right\rangle_{\max }$ reaches a minimum. At this point, the wall shear forces are not able to suppress the turbulent fluctuations further. Consequently, the intermittency again increases to approach unity, showing the combined effect of wake-induced and natural transition due to an increased turbulence intensity level. The damping process of the high turbulence intensity wake flow discussed above explains the phenomena of the becalming effect, a wake induced transition observed by several researchers (Pfeil and Herbst, 1979; Orth, 1992; Schobeiri et al., 1995). Figure 13 also shows the average intermittency that is a result of the integral effect of periodic wakes with respect to time. The maximum intermittency is described by

$$
\langle\gamma(t)\rangle_{\max }=\left(1.0-c_{1} \exp \left[-\left(\frac{\mathbf{R e}_{x}-\mathbf{R e}_{x, \mathrm{~s}}}{\mathbf{R e}_{x, \mathrm{~s}}-\mathbf{R e}_{x, \mathrm{e}}}\right)^{2}\right]\right)
$$


where the constant $c_{1}$ depends on $\Omega$. The minimum intermittency is described by

$$
\langle\gamma(t)\rangle_{\min }=c_{2}\left(1.0-\exp \left[-\left(\frac{\operatorname{Re}_{x}-\mathbf{R e}_{x, \mathrm{~s}}}{\operatorname{Re}_{x, \mathrm{~s}}-\mathbf{R e}_{x, \mathrm{e}}}\right)^{2}\right]\right)
$$

where the constants $c_{2}$ are again dependent on $\Omega$, and the time-averaged intermittency is described by

$$
\bar{\gamma}=c_{4}\left(1.0-c_{3} \exp \left[-\left(\frac{\operatorname{Re}-\operatorname{Re}_{x, \mathrm{t}}}{\operatorname{Re}_{x, \mathrm{t}}-\mathrm{Re}_{x, \mathrm{e}}}\right)^{2}\right]\right) .
$$

The combined effect of $\left\langle\gamma_{i}\left(t_{i}\right)\right\rangle_{\max }$ and $\left\langle\gamma_{i}\left(t_{i}\right)\right\rangle_{\min }$ can be seen in the expression for $\bar{\gamma}$ through the constants $c_{3}$ and $c_{4}$. Table II gives the four constants for the frequencies under investigation. For natural transition, the above constants approach unity.

\section{Freestream Turbulence Intensity}

One major parameter affecting the boundary layer transition onset is the freestream turbulence intensity. The presence of wakes, particularly their spacing and interaction, contribute significantly to an increase of the freestream turbulence. Experimental investigations showed that the freestream timeaveraged turbulence intensity is dependent upon the inlet wake frequency. For the investigated reduced frequency range, it is observed to approach a maximum value of $4.2 \%$ as the wake frequency is increased.

TABLE II Constants in the intermittency correlation

\begin{tabular}{lcccc}
\hline Const & \multicolumn{4}{c}{ Reduced frequency, $\Omega$} \\
\cline { 2 - 5 } & 1.033 & 1.725 & 3.443 & 5.166 \\
\hline$c_{1}$ & 0.57 & 0.22 & 0.50 & 0.35 \\
$c_{2}$ & 0.80 & 0.85 & 0.86 & 0.88 \\
$c_{3}$ & 1.00 & 0.82 & 0.80 & 0.80 \\
$c_{4}$ & 0.85 & 0.92 & 0.92 & 0.94 \\
\hline
\end{tabular}

\subsection{Heat Transfer}

\section{Local Heat Transfer Coefficient Distribution on Concave Surface}

Figure 14 shows the local heat transfer coefficient distribution on the concave and convex surfaces along the longitudinal length of the plate for $\Omega=$ 0.0 ( 0 rods), 1.033 (3 rods), 1.725 (5 rods), 3.443 (10 rods), and 5.166 (15 rods). The effect of the wakes on the heat transfer coefficient can be clearly seen for the concave side of the curved plate. As shown in the figure, the start and end of transition shifts toward the leading edge as the wake passing frequency increases. The beginning of transition occurs for $\Omega=0.0,1.033,1.725,3.443$, and 5.166 around $s / s_{0}=0.35,0.27,0.26,0.21$, and 0.17 ,

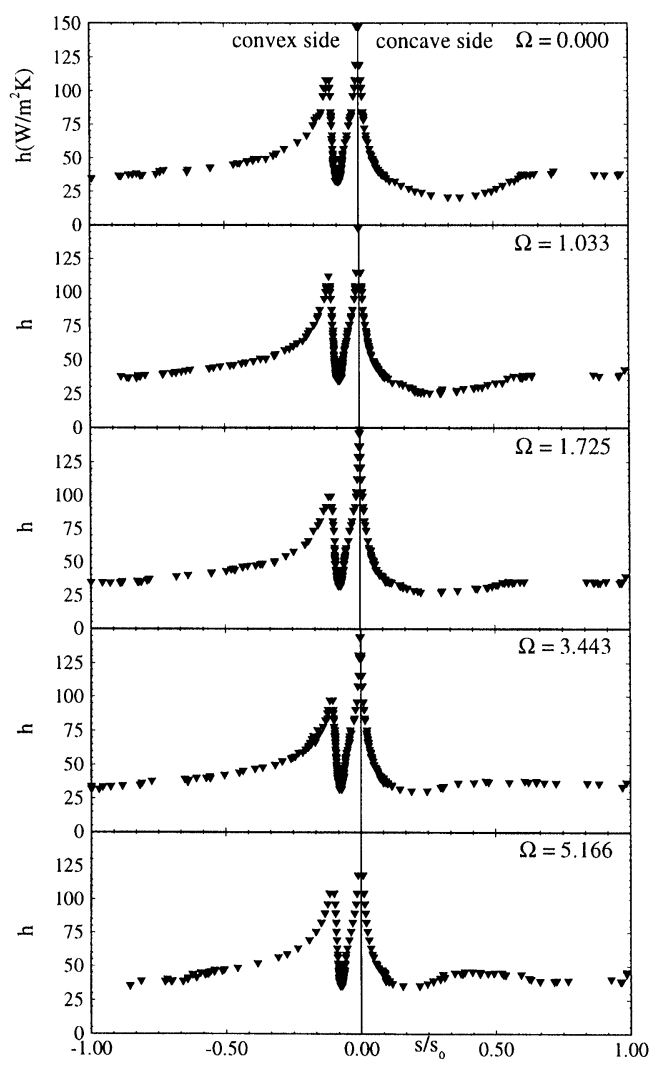

FIGURE 14 Heat transfer coefficient distribution on the concave and convex surface for $\Omega=0.0,1.033$ (3 rods), 1.725 (5 rods), 3.443 (10 rods), 5.166 (15 rods). 
respectively. For these values of $\Omega$, the end of transition occurs around $s / s_{0}=0.63,0.60,0.58$, 0.38 , and 0.34 , respectively. Elevated average heat transfer coefficients occur for higher values of $\Omega$ due to a larger freestream turbulence level generated by stronger wake mixing and turbulent activities inside the boundary layer. In full accord with the aerodynamic picture of the boundary layer transition discussed previously, freestream turbulence predominantly dictates the heat transfer. This agrees with Han et al. (1993), Liu and Rodi (1989), and Wang and Simon (1987). This data also seems to support the work of Simonich and Moffat (1984) and Kestoras and Simon (1993). These researchers found that the time-averaged overall heat transfer coefficient was larger for a concave surface than a flat plate under zero pressure gradient. By comparing the $\Omega=5.166$ case to Liu and Rodi's flat plate investigation, which was run under similar flow conditions, it was found that the heat transfer coefficient is about $10 \%$ greater for the curved plate. This increase may be attributed to the Görtler vortices. However, note that the comprehensive aerodynamic measurements by Schobeiri and Radke (1994), and the present heat transfer investigations, do not show the existence of these vortices. Figure 15 shows the local Nusselt number distribution along the longitudinal length of the

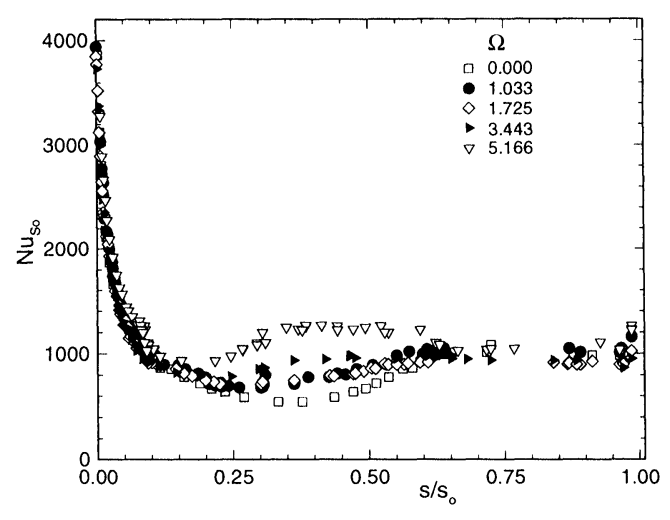

FIGURE 15 Nusselt number distribution on the concave surface of the heat transfer plate for $\Omega=0.000,1.033,1.725,3.443$, and 5.166 . plate for the concave surface. With this figure, the distributions can be easily compared with one another, so that the extent of the effect that an increase in wake passing frequency has upon boundary layer transition can clearly be seen.

\section{Local Heat Transfer Coefficient Distribution on Convex Surface}

For the convex side, the shape of the heat transfer coefficient distribution remains constant for all values of $\Omega$ (positive and negative, i.e., counterclockwise and clockwise rotation of the wake generator). The reason for this is a separation bubble that occurs just downstream of the leading edge of the curved plate. As previously discussed, a flow separation on the convex side of the plate was expected to occur due to an incidence angle of $\beta=-8^{\circ}$ relative to the convex surface. This caused a separation bubble that extended from $s / s_{0}=$ 0.075 to 0.125 . Once the flow finally reattaches, it is fully turbulent, which is evident by the increased heat transfer after reattachment. Thus, the mode of transition is separated flow where a laminar separation/turbulent reattachment bubble is formed as described by Mayle (1991). Figure 16 shows the local Nusselt number distribution along the

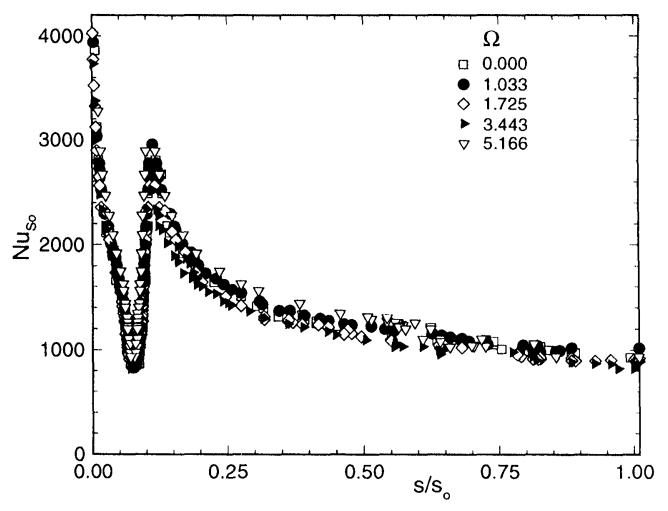

FIGURE 16 Nusselt number distribution on the convex surface of the heat transfer plate for $\Omega=0.000,1.033,1.725$, 3.443 , and 5.166. 
convex surface of the plate with $\Omega$ as parameter. As shown, the unsteadiness associated with higher freestream turbulence intensity does not affect the heat transfer to the convex surface with a separation bubble manifestation.

\section{Comparison between Experimental Results and TEXSTAN}

To help corroborate the results of the liquid crystal technique, the experimental results were compared with numerical results generated by the code TEXSTAN, a program written by Crawford and Kays (1976), which solves steady flow boundary layer equations that govern two-dimensional boundary layer flows. The flows can be laminar, transitional, and turbulent and have either constant or variable properties. TEXSTAN also can handle heat flux and constant temperature boundary conditions. The equations solved by TEXSTAN are the equations of motion, energy, and sufficient auxiliary equations.

The intermittency correlation previously developed is necessary to calculate the unsteady boundary layer transition and heat transfer. However, the liquid crystal technique automatically timeaverages the heat transfer responses. As a result, a time-averaged intermittency correlation implemented into the above code would be more suitable. Crawford recently implemented Mayle's (1991) intermittency model into TEXSTAN, which is a model that incorporates unsteady wake flow into a steady-flow analysis by introducing a timeaveraged intermittency function. Mayle showed that the time-averaged heat transfer distribution on an airfoil surface can be obtained using the timeaveraged turbulence intermittency function. Since unsteady flow was an integral part of the heat transfer investigation, this model was chosen to calculate the start and end of transition. The necessary input for this model is inlet freestream turbulence intensity and inlet velocity taken from the boundary layer data of the heat transfer and aluminum curved plates. However, to achieve the best results with TEXSTAN, the freestream turbulence intensity for each boundary layer traverse had to be averaged. This value was substituted for the inlet turbulence intensity. Mayle's intermittency model defines intermittency $(\gamma)$ as:

$$
\gamma=1-\exp \left[-\tilde{n} \sigma\left(\operatorname{Re}_{x}-\mathbf{R e}_{x t}\right)^{2}\right]
$$

where $\dot{n}=n \nu^{2} / \bar{U}^{3}$ is a dimensionless spot production parameter, $n$ is the turbulent spot production rate, $\sigma$ is Emmon's dimensionless spot propagation parameter, $\operatorname{Re}_{x}=\bar{U} x / \nu$ is the local Reynolds number, and $\operatorname{Re}_{x \mathrm{t}}$ is the local Reynolds number at transition. This equation is used to find the turbulence in the transition region. When $\gamma=0.0$, the flow is completely laminar, but when $\gamma=1.0$, the flow is fully turbulent. The value of the spot production rate $(n \sigma)$ is given as:

$$
\dot{n} \sigma=1.25(10)^{-11} \mathrm{Tu}^{7 / 4}
$$

which is based on a curve fit of intermittency data provided by Kuan and Wang (1989), Gostelow and Ramachandran (1983), and Acharya (1985). The start of transition is determined from Mayle's momentum thickness Reynolds number correlation that is

$$
\operatorname{Re}_{\theta t}=400 \mathrm{Tu}^{-5 / 8}
$$

This correlation was also obtained from a curve fit of the data collected by the aforementioned authors. For a more detailed description of Mayle's intermittency model, refer to Mayle (1991). Besides Mayle's model, the geometry of the heat transfer plate, the heat flux boundary condition, the air properties, and the mode of transition were other major inputs. For the TEXSTAN comparison, turbulent intensities of $1.4 \%, 2.5 \%, 2.7 \%, 3.8 \%$, and $4.5 \%$ that correspond to $\Omega=0.0,1.033$ (3 rods), 1.725 (5 rods), 3.443 (10 rods), and 5.166 (15 rods), respectively, were used in the constant heat flux simulation. Figure 17 shows good agreement between the experimental data and TEXSTAN for $\Omega=1.033,1.725,3.443$, and 5.166. Mixed results 


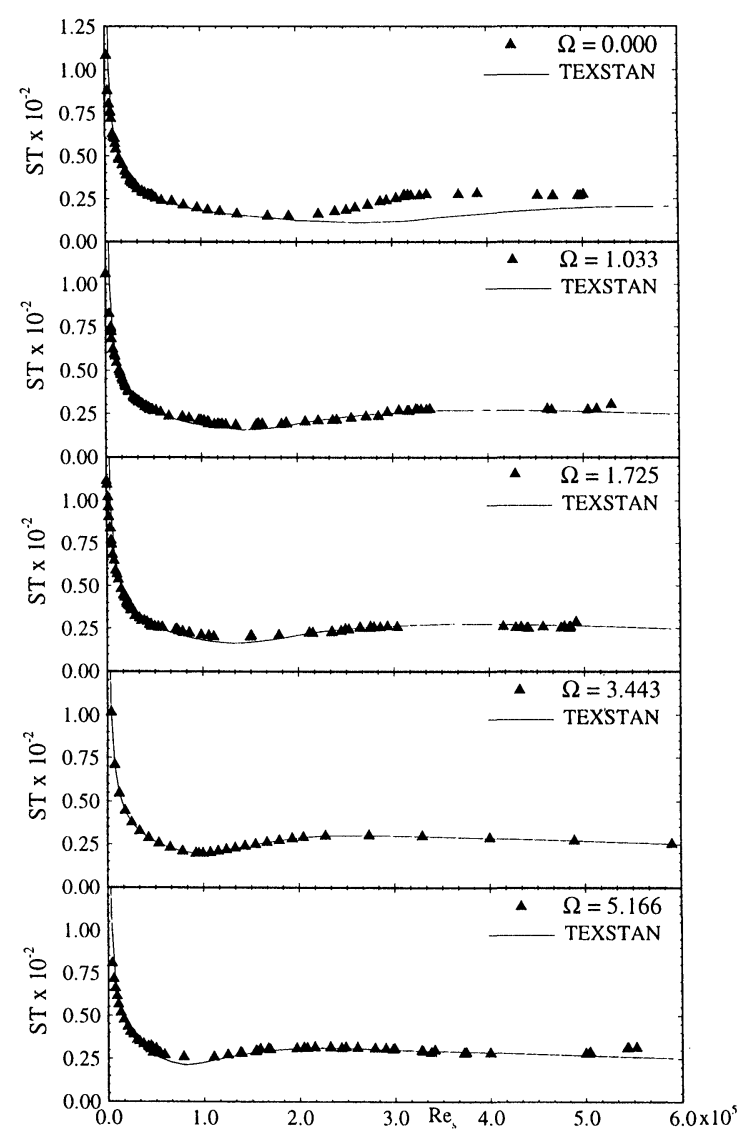

FIGURE 17 Stanton number vs local Reynolds number on the concave surface of the heat transfer plate for all values of $\Omega$.

were found for the steady case. Good agreement was observed for the steady case up to $\mathrm{Re}_{\mathrm{s}}=$ $1.75 \times 10^{5}$, which is the start of transition measured experimentally, then the numerical result deviates from the experimental results. For this case, TEXSTAN over predicts the start of transition. This disagreement is primarily due to the curve-fit correlations of $n \sigma$ and $\mathrm{Re}_{\theta t}$ where both have a larger curve-fit error at low turbulent intensities $(<1.5 \%)$ due to the non-linearity in the curve-fit data at low turbulent intensities (see Mayle, 1991).

There is generally good agreement when the Stanton number distribution is compared with other heat transfer investigations involving a concave surface. The magnitude of the Stanton number in the turbulent region compares favorably with the results of Mayle et al. (1979) where the heat transfer of a turbulent boundary layer on a concave surface was investigated. Both the transition and turbulent regions of the steady case compare well in magnitude and trend to the results of Kestoras and Simon (1993). Kestoras and Simon had a similar inlet velocity, but a lower turbulence intensity $(\mathrm{Tu}=0.68 \%)$ as opposed to the $1.2 \%$ for the steady case in this investigation. The curved plate, however, was different. Kestoras and Simon had a longer curved plate with less curvature. Due to the lower turbulence intensity, the rise in Stanton number in the transition region was greater but peaked at the same magnitude as in this investigation. Simonich and Moffat (1984) also studied the effects of concave curvature on turbulent boundary layers. They found Stanton numbers in the turbulent region to be about $50 \%$ less than those in this investigation. The discrepancy is most likely due to their radius of curvature being twice that of the radius of curvature of the heat transfer plate and their different inlet conditions.

\section{UNCERTAINTY ANALYSIS}

The Kline and McClintock (1953) uncertainty analysis method was used to determine the uncertainty in the velocity after calibration and data reduction for the single-wire probe. In addition, the uncertainty in the heat transfer measurements was also determined. Note that the determined uncertainty may not be the actual uncertainty of the results because the Kline and McClintock method determines the worst possible uncertainty. The uncertainty in velocity for the single-wire probe after data reduction is given in Table III.

As shown, the uncertainty in velocity increases as the flow velocity decreases. This is due to the pneumatic pressure transducer having a large uncertainty during calibration. The maximum uncertainty in the local heat transfer coefficient for all 
TABLE III Uncertainty in velocity measurement for hot-wire probe

\begin{tabular}{llll}
\hline$v(\mathrm{~m} / \mathrm{s})$ & 3 & 5 & 12 \\
$\pm \Delta v_{\mathrm{e}}(\mathrm{m} / \mathrm{s})_{\text {red }}$ & 5.78 & 2.41 & 1.40 \\
\hline
\end{tabular}

the rod cases was approximately $\pm 2.87 \mathrm{~W} / \mathrm{m}^{2} \mathrm{~K}$. Regarding position, there is a $\pm 1.0 \mathrm{~mm}$ uncertainty in the determination of the yellow band region.

\section{CONCLUSIONS}

The effect of periodic unsteady wakes on boundary layer transition on the concave side of a constant curvature curved plate under zero pressure gradient was experimentally investigated in a subsonic wind tunnel test facility. In addition, the effect that these wakes have on the heat transfer on the concave and convex surfaces was experimentally investigated in the same test facility. For both experiments, the same wake passing frequency was used so a comparison could be made between the aerodynamic and heat transfer data. From this investigation, the following conclusions were drawn:

(1) The intermittency analysis showed that the relative intermittency function is seen to follow a Gaussian distribution. The minimum intermittency factor, $\left\langle\gamma_{\min }\right\rangle$, represents the boundary layer behavior between the turbulent wake strips. It is shown to follow the natural transition process as the free-stream is almost non-turbulent. On the other hand, $\left\langle\gamma_{\max }\right\rangle$ being the value inside the turbulent core, starts with a value of 1.0 and goes through a minimum. This is due to the viscous damping of the turbulent core by the boundary layer.

(2) Increasing wake passing frequency results in earlier transition and approximately equal transition zones. At $\Omega=1.033$ (3 rods) and $\Omega=1.725$ (5 rods), the isolated unsteady wakes showed no visible interaction with each other.
Visible wake interaction is present at $\Omega=3.443$ (10 rods) and $\Omega=5.166$ (15 rods) simulating the flow through the third and fourth rows of a multistage turbine. This shows that the research is applicable to actual turbomachines.

(3) Higher turbulence intensity occurs when increasing the unsteady parameter $\Omega$ due to the intense mixing of the primary and secondary wakes at higher values of $\Omega$. At higher turbulence levels, the start of transition is closer to the leading edge of the curved plate.

(4) On the concave surface of the heat transfer plate, increasing the unsteady parameter $\Omega$ results in earlier transition and a higher average heat transfer coefficient.

(5) Increasing the unsteady parameter $\Omega$ has no effect upon a laminar separation/turbulent reattachment bubble on the convex surface at turbulent intensities ( $x$-component) less than $5 \%$.

(6) Considering the transition onset, the hot-wire and heat transfer data were in good agreement with each other, which says that the liquid crystal technique delivers accurate and dependable results. In addition, the time-averaged heat transfer results are predicted well by TEXSTAN using Mayle's time-averaged intermittency correlations.

\section{Acknowledgment}

The authors would like to express their sincere thanks and appreciation to Dr. R. Simoneau, Chief of Heat Transfer Branch, NASA Lewis Research Center, Mr. Steve Hippensteele, heat transfer research engineer, and Mrs. B. Lucci, the project monitor. They also thank the administration of the NASA Lewis Research Center for their continuous cooperation and support of this project. The authors would also like to thank Dr. M. Crawford, Professor at the University of Texas at Austin, for information he provided on his program TEXSTAN. 


\section{NOMENCLATURE}

$b \quad$ Intermittency width

$C_{\mathrm{d}} \quad$ Drag coefficient

$d \quad$ Lateral distance above the plate surface, $d=10 \mathrm{~mm}$

$d_{\mathrm{R}} \quad$ Rod diameter

$h \quad$ Heat transfer coefficient

I Current

$\mathrm{Nu} \quad$ Nusselt number

$Q \quad$ Heat added

$s \quad$ Streamwise position

$s_{0} \quad$ Arc length of concave surface of curved plate, $s_{0}=690 \mathrm{~mm}$

$s_{\mathrm{R}} \quad$ Rod spacing

St Stanton number

$\mathrm{Tu}_{\mathrm{ref}} \quad$ Reference turbulence intensity

$\mathrm{Tu}_{\mathrm{loc}} \quad$ Local turbulence intensity

$\langle\mathrm{Tu}\rangle \quad$ Ensemble-averaged reference turbulence intensity

$U_{\text {ref }} \quad$ Reference local velocity at a distance of $d=10 \mathrm{~mm}$

$\langle U\rangle \quad$ Ensemble-averaged velocity

$U \quad$ Instantaneous velocity

$\bar{U} \quad$ Time-averaged velocity

$\bar{U}_{\mathrm{w}}$ Circumferential velocity of wake generator

$U_{\text {ref }} \quad$ Reference local velocity at a distance of $d=10 \mathrm{~mm}$

$u \quad$ Turbulent fluctuation component

$u_{\tau} \quad$ Shear stress velocity

V Voltage

$\langle u\rangle \quad$ Ensemble-averaged fluctuation velocity $(\mathrm{m} / \mathrm{s})$

$y \quad$ Lateral distance from plate surface

$y^{+} \quad$ Non-dimensional wall distance, $y^{+}=u_{\tau} y / v$

$\nu \quad$ Kinematic viscosity of air

$\epsilon \quad$ Emissivity

$\sigma \quad$ Stefan-Boltzmann constant in Eq. (7)

$\sigma \quad$ Spot propagation parameter in Eq. (16)

$\tau \quad$ One wake passing period

$\phi \quad$ Flow coefficient $\phi=U_{\text {in }} / U_{\mathrm{w}}$

$\Omega \quad$ Unsteady parameter $\Omega=\left(C_{\mathrm{D}} s_{0} U_{\mathrm{w}}\right) /$ $\left(s_{\mathrm{R}} U_{\mathrm{in}}\right)$

\section{References}

Acharya, M. (1985) Pressure-Gradient and Free-stream Turbulence Effects on Boundary Layer Transition, Brown Boveri Forschungszentrum, Baden, Switzerland, Forschungsbericht KLR 85-127C.

Addison, J.S. and Hodson, H.P. (1990a) Unsteady transition in an axial-flow turbine: Part I - Measurements on the turbine rotor, ASME Journal of Turbo Machinery, 112, 206-214.

Addison, J.S. and Hodson, H.P. (1990b) Unsteady transition in an axial-flow turbine: Part 2 - Cascade measurements and modeling, ASME Journal of Turbo Machinery, 112, 215-221.

Ashworth, D.A., LaGraff, J.E. and Schultz, D.L. (1989) Unsteady interaction effects on a transitional turbine blade boundary layer, ASME Journal of Turbo Machinery, 111, $162-168$.

Crane, R.I. and Sabzvari, J. (1989) Heat transfer visualization and measurement in unstable concave-wall laminar boundary layers, Journal of Turbo Machinery, 111, 51-56.

Crawford, M.E. and Kays, W.M. (1976) STANS (TEXSTAN version) - A program for numerical computation of two dimensional internal and external boundary layer flow, NASA CR-2742.

Doorly, D.J., Oldfield, M.L.G. and Scrivener, C.T.J. (1985) Wake-passing in a turbine rotor cascade, Heat Transfer and Cooling in Gas Turbines, AGARD-DP-390, 7-1 to 7-18.

Doorly, D.J. (1988) Modeling the unsteady flow in a turbine rotor passage, ASME Journal of Turbo Machinery, 110 , $27-37$.

Dring, R.P., Blair, M.F., Joslyn, H.D., Power, G.D. and Verdon, J.M. (1986) The effect of inlet turbulence and rotor/stator interactions on the aerodynamics and heat transfer of a large scale rotating turbine model, NASA CR 4079.

Dullenkopf, K., Schulz, A. and Wittig, S. (1991) The effect of incident wake conditions on the mean heat transfer of an airfoil, Journal of Turbo Machinery, 113, 412-418.

Dunn, M.G. (1986) Heat flux measurements for the rotor of a full-stage turbine: Part I - Time averaged results, $A S M E$ Journal of Turbo Machinery, 108, 90-97.

Gaugler, R. (1985) A review and analysis of boundary layer transition data for turbine application, ASME Paper No. 85GT-83.

Gostelow, J.P. and Ramachandran, R.M. (1983) Some effects of free stream turbulence on boundary layer transition, Proceedings of 8 th Austral Asian Fluid Mechanics Conference.

Han, J.C., Zhang, L. and Ou, S. (1993) Influence of unsteady wake on heat transfer coefficient from a gas turbine blade, Journal of Heat Transfer, 115, 904-911.

Hedley, B.T. and Keffer, F.J. (1974) Turbulent/non-turbulent decisions in an intermittent flow, Journal of Fluid Mechanics, 64, 625-644.

Hippensteele, S.A., Russell, L.M. and Stepka, F.S. (1983) Evaluation of a method for heat transfer measurements and thermal visualization using a composite of a heater element and liquid crystals, ASME Journal of Heat Transfer, 105, 184-189.

Hippensteele, S.A., Russell, L.M. and Torres, F.J. (1985) Local heat transfer measurements on a Large, Scale-model Turbine Blade Airfoil using a Composite of a heater element and liquid crystals. NASA TM-86900.

Hodson, H.P. (1984) Measurement of wake-generated unsteadiness in the rotor passage of axial flow turbines, ASME Paper No. 84-GT-189. 
John, J. and Schobeiri, T. (1993) A simple and accurate method of calibrating X-probes, Journal of Fluids Engineering, 115 , $148-152$.

Kestoras, M.D. and Simon, T. (1993) Combined effects of concave curvature and high free-stream turbulence intensity of boundary layer heat and momentum transport, ASME Paper No. 93-WA/HT-56.

Kline, S.J. and McKlintock, F.A. (1953) Describing uncertainties in single-sample experiments, Mechanical Engineering, 75, 3-8.

Kuan, C. and Wang, T. (1989) Some intermittent behavior of transitional boundary layer, AIAA Paper No. 89-1890.

LaGraff, J.E., Ashworth, D.A. and Schultz, D.L. (1989) Measurement and modeling of the gas turbine blade transition process as disturbed by wakes, ASME Journal of Turbo Machinery, 111, 315-322.

Liu, X. and Rodi, W. (1989) Measurement of unsteady flow over and heat transfer from a flat plate, ASME Paper No. 89-GT-2.

Liu, X. and Rodi. W. (1992) Measurement of unsteady flow and heat transfer in a linear turbine cascade, ASME Paper No. 92GT-323.

Mayle, R.E., Blair, M.F. and Kopper, F.C. (1979) Turbulent boundary layer heat transfer on curved surfaces, Journal of Heat Transfer, 101, 521-525.

Mayle, R.E. and Dullenkopf, K. (1989) A theory for wakeinduced transition, ASME Journal of Turbo Machinery, 112 $188-195$.

Mayle, R.E. (1991) The role of laminar-turbulent transition in gas turbine engines, Journal of Turbo Machinery, 113, 509-537.

Mayle, R.E. and Dullenkopf, K. (1991) More on the turbulentstrip theory for wake-induced transition, ASME Journal of Turbo Machinery, 113, 428-432.

Narasimha, R. (1957) On the distribution of intermittency in the transition region of a boundary layer, J. Aero, Sci., 24, $711-712$.

Orth, U. (1992) Unsteady boundary-layer transition in flow periodically disturbed by wakes, ASME Paper No. 92GT-283.

Pfeil, H. and Herbst, R. (1979) Transition procedure of instationary boundary layers, ASME Paper No. 79-GT-128.

Pfeil, H., Herbst, R. and Schröder, T. (1983) Investigation of the laminar-turbulent transition of boundary layers disturbed by wakes, ASME Journal of Engineering for Power, 105, 130-137.

Russell, L.M., Hippensteele, S.A. and Poinsatte, P.E. (1993) Measurements and computational Analysis of heat transfer and flow in a Simulated turbine blade internal cooling passage, NASA TM-106189.

Schobeiri, M.T., McFarland, E. and Yeh, F. (1991) Aerodynamic and heat transfer investigations on a high reynolds number turbine cascade, ASME Paper No. 91-GT-157.
Schobeiri, T. and Pardivala, D. (1992) Development of a subsonic flow research facility for simulating the Turbo machinery flow and investigating its effects on boundary layer transition, Wake Development and Heat Transfer, Fourth International Symposium on Transport Phenomena and Dynamics of Rotating Machinery, Washington D.C., pp. 98-114.

Schobeiri, T. and Radke, R. (1994) Effects of periodic unsteady wake flow and pressure gradient on boundary layer transition along the concave surface of a curved plate, ASME Paper No. 94-GT-327.

Schobeiri, T., Read, K. and Lewalle, J. (1995a) Effect of unsteady wake passing frequency on boundary layer transition, experimental investigation and wavelet analysis, ASME Paper No. 95-GT-437.

Schobeiri, T., Pappu, K. and Wright, L. (1995b) Experimental study of the unsteady boundary layer behavior on a turbine cascade, submitted for presentation at the IGTI-Conference in Houston, 1995.

Schobeiri, M.T., John, J. and Pappu, K. (1996) Development of two-dimensional wakes within curved channels, Theoretical Framework and Experimental Investigation, ASME Transactions, Journal of Turbomachinery, 118, $506-518$.

Sharma, O.P., Renaud, E., Butler, T.L., Milsaps Jr., K., Dring, R.P. and Joslyn. H.D. (1988) Rotor-Stator interaction in axial-flow turbines, AIAA Paper No. 88-3013.

Simonich, J.C. and Moffat, R.J. (1984) Liquid crystal visualization of surface heat transfer on a concavely curved turbulent boundary layer, Journal of Engineering for Gas Turbines and Power, 106, 619-627.

Speidel, L. (1957) Effect of periodic disturbances of the upstream flow on the laminar boundary layer, Zeitschrift für Flugwissenschaften, Vol. 9.

Walker, G.J. (1974) The unsteady nature of boundary layer transition on an axial-flow compressor blade, ASME Paper No. 74-GT-135.

Wang, T. and Simon, T.W. (1987) Heat transfer and fluid mechanics measurements in transitionl boundary layers on convex-curved surfaces, Journal of Turbomachinery, 109, 443-451.

Wittig, S., Schultz, A., Dullenkopf. K. and Fairbank, J. (1988) Effects of free-stream turbulence and wake characteristics on the heat transfer along a cooled gas turbine blade, ASME Paper No. 88-GT-179.

You, S.M., Simon, T.W. and Kim, J. (1989) Free-stream turbulence effects on convex-curved turbulent boundary layers, Journal of Heat Transfer, 111, 66-76. 


\section{ait \\ ENERGY MATERIALS}

M A N E Y publishing

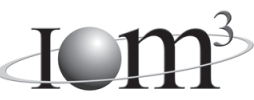

\section{Materials Science \& Engineering for Energy Systems}

Maney Publishing on behalf of the Institute of Materials, Minerals and Mining

The Institute of Materials, Minerals \& Mining

Economic and environmental factors are creating ever greater pressures for the efficient generation, transmission and use of energy. Materials developments are crucial to progress in all these areas: to innovation in design; to extending lifetime and maintenance intervals; and to successful operation in more demanding environments. Drawing together the broad community with interests in these areas, Energy Materials addresses materials needs in future energy generation, transmission, utilisation, conservation and storage. The journal covers thermal generation and gas turbines; renewable power (wind, wave, tidal, hydro, solar and geothermal); fuel cells (low and high temperature); materials issues relevant to biomass and biotechnology; nuclear power generation (fission and fusion); hydrogen generation and storage in the context of the 'hydrogen economy'; and the transmission and storage of the energy produced.

As well as publishing high-quality peer-reviewed research, Energy Materials promotes discussion of issues common to all sectors, through commissioned reviews and commentaries. The journal includes coverage of energy economics and policy, and broader social issues, since the political and legislative context influence research and investment decisions.

\section{CALL FOR PAPERS}

Contributions to the journal should be submitted online at http://ema.edmgr.com

To view the Notes for Contributors please visit: www.maney.co.uk/journals/notes/ema

Upon publication in 2006, this journal will be available via the Ingenta Connect journals service. To view free sample content online visit: www.ingentaconnect.com/content/maney

For further information please contact:

Maney Publishing UK

Tel: +44 (0)113 2497481 Fax: +44 (0)1132486983 Email: subscriptions@maney.co.uk

or

Maney Publishing North America

Tel (toll free): 8662975154 Fax: 6173546875 Email: maney@maneyusa.com

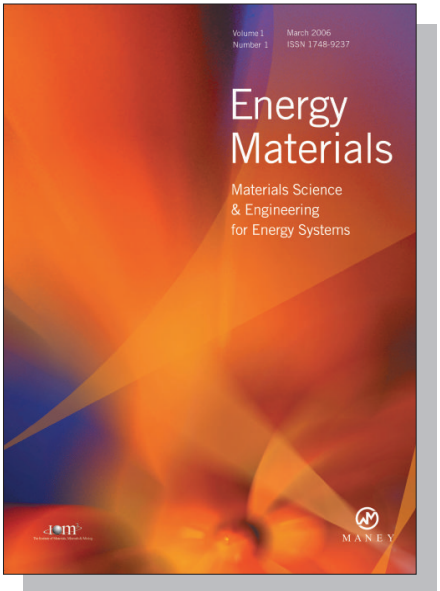

EDITORS

Dr Fujio Abe

NIMS, Japan

Dr John Hald, IPL-MPT, Technical University of Denmark, Denmark

Dr R Viswanathan, EPRI, USA

\section{SUBSCRIPTION INFORMATION}

Volume 1 (2006), 4 issues per year

Print ISSN: 1748-9237 Online ISSN: 1748-9245

Individual rate: $£ 76.00 / U S \$ 141.00$

Institutional rate: $£ 235.00 /$ US $\$ 435.00$

Online-only institutional rate: $£ 199.00 / U S \$ 367.00$

For special $\mathrm{IOM}^{3}$ member rates please email

subscriptions@maney.co.uk

\section{For further information or to subscribe online please visit www.maney.co.uk}



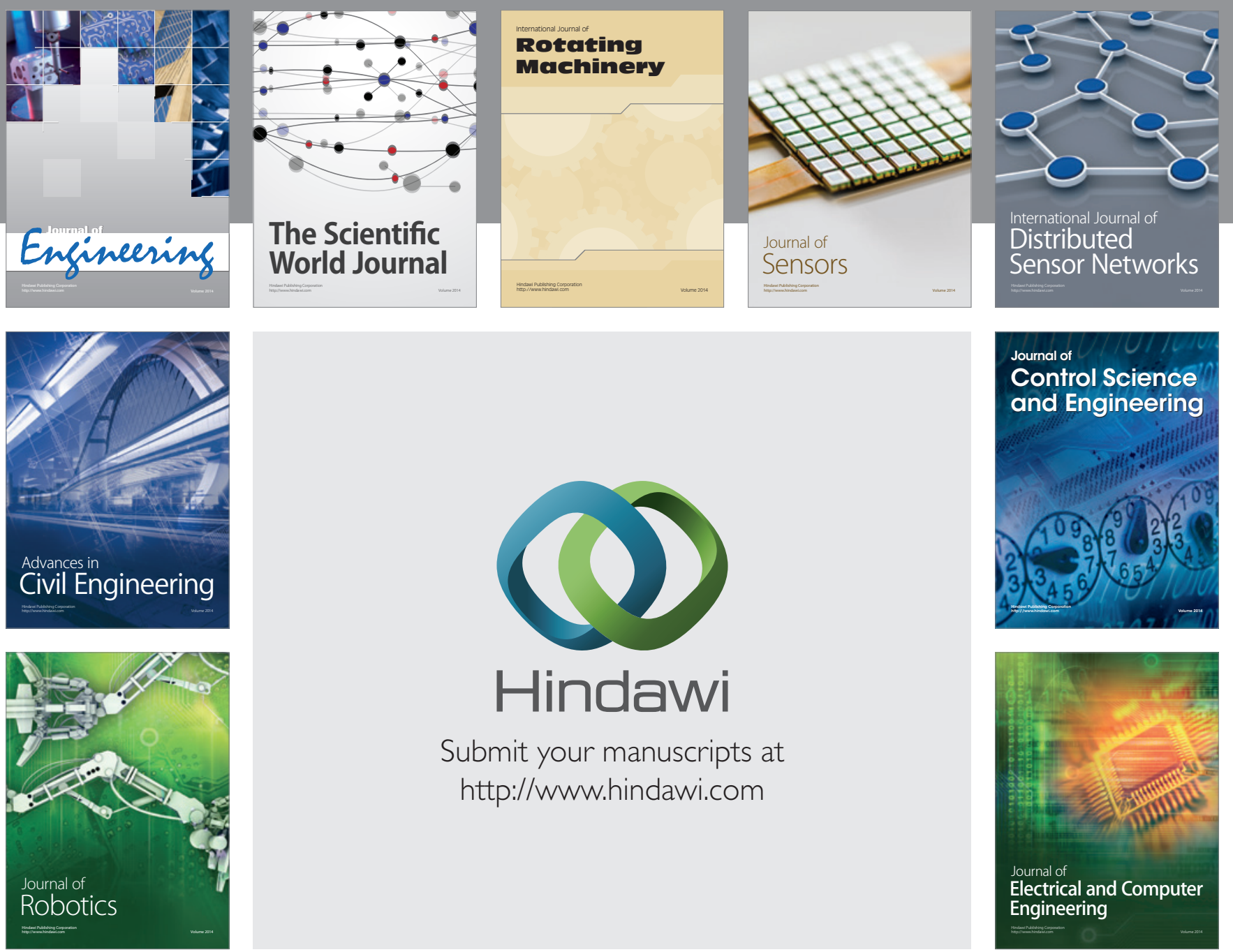

Submit your manuscripts at

http://www.hindawi.com
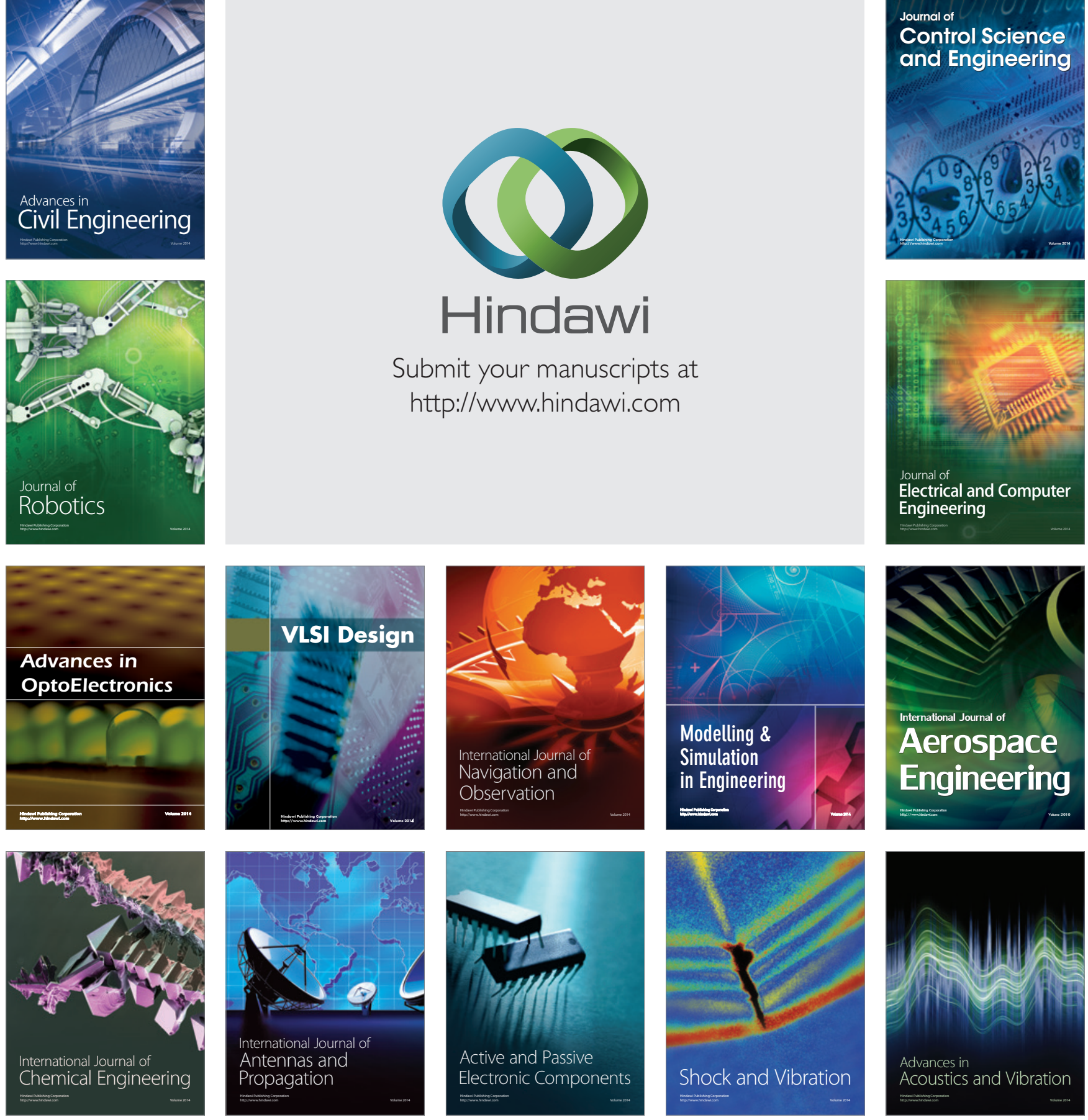